Article

\title{
Effect of Nano-Montmorillonite on Osteoblast Differentiation, Mineral Density, and Osteoclast Differentiation in Bone Formation
}

\author{
Gyeong-Ji Kim ${ }^{1,2,+}$, Daniel Kim ${ }^{3, \dagger}{ }^{+}$Kwon-Jai Lee ${ }^{4}$, Daeyoung Kim ${ }^{5}$, Kang-Hyun Chung ${ }^{6}$, \\ Jeong Woo Choi $2,7, *$ and Jeung Hee An $1, *$ (D) \\ 1 Department of Food and Nutrition, KC University, Seoul 07661, Korea; kgj8495@hanmail.net \\ 2 Department of Biomedical Engineering, Sogang University, Seoul 04107, Korea \\ 3 Advanced Geo-materials R\&D Department, Pohang Branch, Korea Institute of Geoscience and Mineral \\ Resources, Pohang 37559, Korea; daniel@kigam.re.kr \\ 4 Department of Advanced Materials Engineering, Daejeon University, Daejeon 34520, Korea; jmul@ssu.ac.kr \\ 5 Department of Nanomaterials Science and Engineering, University of Science and Technology, \\ Daejeon 34113, Korea; daeyoung@kigam.re.kr \\ 6 Department of Food Science and Technology, Seoul National University of Science \& Technology, \\ Seoul 01811, Korea; carl@seoultech.ac.kr \\ 7 Department of Chemical and Biomolecular Engineering, Sogang University, Seoul 04107l, Korea \\ * Correspondence: jwchoi@sogang.ac.kr (J.W.C.); anjhee@hanmail.net (J.H.A.); Tel.: +82-2-718-11976 (J.W.C.); \\ $+82-2-2600-2566$ (J.H.A.) \\ + These authors contributed equally to this work.
}

Received: 4 December 2019; Accepted: 26 January 2020; Published: 28 January 2020

check for updates

\begin{abstract}
Calcium-type montmorillonite, a phyllosilicate mineral, has diverse health benefits when introduced into the gastrointestinal tract or applied to the skin. However, the predominant use of this layered material has thus far been in traditional industries, despite its potential application in the pharmaceutical industry. We investigated the effects and mechanism of nano-montmorillonite (NM) on osteoblast and osteoclast differentiation in vivo and in vitro. We examined the osteogenic effects of NM with high calcium content (3.66 wt \%) on alkaline phosphatase (ALP) activity, mineralization, bone microarchitecture, and expression level of osteoblast and osteoclast related genes in Ca-deficient ovariectomized (OVX) rats. Micro-computed tomography of OVX rats revealed that NM attenuated the low-Ca-associated changes in trabecular and cortical bone mineral density. It improved ALP activity and mineralization, as well as the expression of osteoblast and osteoclast differentiation associated genes. NM also activated the expression of runt-related transcription factor 2, osteocalcin, bone morphogenetic protein 2, and type 1 collagen via phosphorylated small mothers against decapentaplegic homolog 1/5/8 signaling. Further, NM repressed the expression of receptor activator for cathepsin K, nuclear factor kappa-B ligand and tartrate-resistant acid phosphatase. Therefore, NM inhibits osteoclastogenesis, stimulates osteoblastogenesis, and alleviates osteoporosis.
\end{abstract}

Keywords: nano-montmorillonite; bone formation; osteoblasts; osteoclasts; ovariectomy rats

\section{Introduction}

Montmorillonite - a predominantly dioctahedral smectite — is a charged, layered silicate mineral and the main component of "bentonite" [1-3]. Bentonite is mainly included of montmorillonite and minor minerals, such as feldspar, albite, and quartz, depending on the geological environment [4]. Bentonite ore has thus far been widely used as drilling mud, animal feed additive, adsorbent, and soil improvement agent [5-8]. Recently, nearly pure montmorillonite purified from bentonite has been 
extensively studied for its use in cosmetics, natural therapies, and pharmaceuticals [9-12], owing to its specific properties such as high swelling pressure, high cation exchange capacity, and high adsorption ability [13-15]. In pharmaceutical applications, montmorillonite was found to have an active role in dermatological protection and anti-inflammation, and as an antidiarrheal and antacid [16-19]. Oral administration of montmorillonite as a dietary supplement showed protection against high-fat diet-induced dysbiosis of gut microbiota in mouse and prevention of obesity, by enhancing lipid excretion from the digestive tract in rats [20,21]. Recently, the effect of clay montmorillonite and sodium silicate was studied in human mesenchymal stem cells in osteogenic culture to confirm its role as a biomaterial [22]. The use of montmorillonite for bone therapy has also been reported, such as in engineered scaffolds with cytocompatibility, improving thermal stability, and increasing cellular proliferation rates $[23,24]$.

Osteoporosis is a disease prevalent in postmenopausal women and is characterized by progressive loss of bone mineral density (BMD), suppressed bone strength, and enhanced fracture risk [25]. Deficiency of estrogen due to halted ovarian function is a pivotal role in the loss of bone mass in postmenopausal women [26]. Pathological factors for osteoporosis include imbalanced calcium (Ca) metabolism, decreased osteoblast activity, increased osteoclast function, and deficient estrogen production $[27,28]$. Generally, Ca has an important role in the human body, with various physiological functions. Ca is involved in structural support, muscle contraction, bone strength, blood clotting, and heartbeat regulation [29]. Ca intake induce to an increase in BMD and can suppress the risk of fracture and osteoporosis [30]. Clinical research has many interested in fracture prevention and treatment for the improvement of BMD [31]. Previous studies have investigated the use of Ca supplements such as calcium lactate, calcium citrate, and calcium carbonate extracted from foods [32-34]. Anke et al. (1992) showed that goats fed a ration of bentonite had decreased Ca, phosphorus, and sodium content in bone [35]. Dembinski et al. (1985) found that supplementation of bentonite at $2000 \mathrm{mg} / \mathrm{kg}$ body weight in hybrid goats decreased Ca deposition in bone [36]. However, studies on the bone formation mechanism of montmorillonite have not been reported.

The objective of this study was to observe the in vitro and in vivo effects of nano-montmorillonite (NM) on bone remodeling by osteoblastogenesis and osteoclastogenesis. We demonstrate here, for the first time, by modulating osteoblast and osteoclast-specific genes, transcription factors, and signaling molecules, that NM promotes osteoblast differentiation via bone morphogenetic protein 2 (BMP-2)/phosphorylated small mothers against decapentaplegic homolog 1/5/8 (p-SMAD $1 / 5 / 8$ )/runt-related transcription factor 2 (RUNX2) expression and suppresses osteoclast differentiation via tartrate-resistant acid phosphatase (TRAP)/receptor activator of nuclear factor kappa-B (RANK). Our results suggest that NM could open a new field of study of mineral materials and the application of these materials in the treatment of osteoporosis.

\section{Materials and Methods}

\subsection{Preparation of $N M$}

Natural bentonite was collected from the Gampo-40 mining site located in Gyeongju, South Korea. Montmorillonite was purified from fresh bentonite by a sedimentation and segregation processes for particle sizes $\leq 5 \mu \mathrm{m}$, followed by oven drying at $80^{\circ} \mathrm{C}$ overnight. To prepare the NM suspension used in this study, purified montmorillonite $(6.2 \mathrm{mg})$ was dispersed in deionized water $(1 \mathrm{~mL})$ by sonication with glass beads for $3 \mathrm{~h}$.

\subsection{Powder X-Ray Diffraction (XRD)}

The powder XRD pattern was determined using a Rigaku Mini Flex 600 diffractometer with $\mathrm{Cu}$ $\mathrm{K} \alpha$ radiation $(\lambda=1.5406 \AA)$ at $40 \mathrm{kV}$ and $15 \mathrm{~mA}$. Data were collected over a $2 \theta$ range of $2^{\circ}$ to $70^{\circ}$, with a step size of $0.02^{\circ}$. Indexing of the obtained XRD patterns was analyzed by the Crystallographica Search-Match (CSM) software (Oxford Cryosystems, Oxford, UK). 


\subsection{Scanning Electron Microscopy (Sem) and Energy Dispersive X-Ray Spectroscopy (EDS)}

Purified montmorillonite was coated with palladium, and the morphology and atomic ratio of the sample were investigated by SEM (Model EVO LS25, ZIESS), operating at $10 \mathrm{kV}$, equipped with an energy dispersive $X$-ray spectrometer (EDS, NORAN SYSTEM7, Thermo Scientific).

\subsection{Particle Size Analysis}

The particle size and distribution of the NM suspension were measured using a Microtrac S3500 Bluewave Laser Diffraction instrument.

\subsection{Cell Culture}

Osteoblast-like cell (MG-63) and osteoclast cell (RAW 264.7) (Korean Cell Bank, Seoul, Korea) were grown in Roswell Park Memorial Institute (RPMI) medium or Dulbecco's modified Eagle's medium (DMEM) supplemented with fetal bovine serum (FBS, 10\%; Hyclone, Logan, UT, USA) and penicillin-streptomycin (1\%; GIBCO, Grand Island, NY, USA) in a $\mathrm{CO}_{2}(5 \%)$ incubator at $37^{\circ} \mathrm{C}$.

\subsection{Cell Viability Assay}

MG-63 $\left(5 \times 10^{4}\right.$ cells $\left./ \mathrm{mL}\right)$ and RAW $264.7\left(5 \times 10^{4}\right.$ cells $\left./ \mathrm{mL}\right)$ cells were differentiated in a 96-well plate. The cell viability was determined by 3-(4,5-dimethylthiazol-2-yl)-2,5-diphenyltetrazolium bromide (MTT; Promega, Madison, WI, USA) analysis. The cells were treated with various concentrations $(250-1000 \mu \mathrm{g} / \mathrm{mL})$ of NM for $24 \mathrm{~h}$. After $24 \mathrm{~h}$ of exposure, the $20 \mu \mathrm{L}$ of MTT solution $(5 \mathrm{mg} / \mathrm{mL})$ was added. After $4 \mathrm{~h}$, the formazan crystals had formed and dissolved in $200 \mu \mathrm{L}$ of dimethyl sulfoxide (DMSO). Then, the absorbance of the resulting solution was evaluated based on the optical density values measured at $540 \mathrm{~nm}$ using a microplate reader (Biochrom Asys, Cambridge, UK).

\subsection{Analysis of Alkaline Phosphatase (ALP) Activity}

The ALP activity was analyzed as the rate of $p$-nitrophenyl phosphate (p-NPP) hydrolysis. MG-63 cells $\left(5 \times 10^{4}\right.$ cells $\left./ \mathrm{mL}\right)$ were seeded in 96 -well plates. For induction and cell differentiation, cells were treated with $\beta$-glycerol phosphate $(10 \mathrm{mM})$ and ascorbic acid $(50 \mathrm{mg} / \mathrm{mL})$ and the indicated concentrations of NM for 7 days. The cells were lysed in Triton X-100 (0.1\%), and incubated with p-NPP at $37^{\circ} \mathrm{C}$ for $60 \mathrm{~min}$. Then, the ALP activity was measured at $405 \mathrm{~nm}$ using a microplate reader.

\subsection{Bone Mineralization Analysis Using Alizarin Red S Staining}

The mineralization was determined after 14 days of treatment with differentiation medium and NM. For Alzarin red S staining, the MG-63 cells were fixed in 70\% ethanol for $1 \mathrm{~h}$, incubated with alizarin red S (40 mM) in deionized water ( $\mathrm{pH} 4.2)$ for $15 \mathrm{~min}$. Then, the cells were washed the PBS, and then de-stained for $15 \mathrm{~min}$ with cetylpyridinium chloride $(10 \% \mathrm{w} / \mathrm{v})$ in sodium phosphate $(10 \mathrm{mM}$, $\mathrm{pH}$ 7.0). The absorbance was measured at $550 \mathrm{~nm}$ using a microplate reader.

\subsection{Tartrate-Resistant Acid Phosphatase (Trap) Activity and Staining}

RAW 264.7 cells $\left(5 \times 10^{4}\right.$ cells $\left./ \mathrm{mL}\right)$ were seeded in 96 -well plates. Five days after stimulating the cells with RANK ligand (RANKL, $50 \mathrm{ng} / \mathrm{mL}$ ), the cells were washed with PBS. To measure TRAP activity, the cells were fixed in 3.5\% formaldehyde for $10 \mathrm{~min}$. Then, the cells rinsed with distilled water, and incubated in citrate buffer $(50 \mathrm{mM}, \mathrm{pH} 4.5)$ containing sodium tartrate $(10 \mathrm{mM})$ and $\mathrm{p}$-NPP $(6 \mathrm{mM})$. After $1 \mathrm{~h}$, the mixtures solution was transferred to new 96-well plates containing an equal volume of $\mathrm{NaOH}(0.1 \mathrm{~N})$. The absorbance was measured at $405 \mathrm{~nm}$ in a microplate reader. The cells were stained for TRAP by a leukocyte acid phosphatase assay kit (Sigma), following the manufacturer. 


\subsection{Animals and Diet}

All animal experiments were performed with the approval from the Institutional Animal Care and Use Committee at Konkuk University (IACUC approval number KU 15133). Female Wistar rats weighing $117 \pm 7 \mathrm{~g}$ and aged 5 weeks (Doo Yeol Biotech, Seoul, Korea) were used in this study. The animals were maintained in a room at $22{ }^{\circ} \mathrm{C}$ with a $12 \mathrm{~h}$ light-dark cycle. After acclimatization for one week, the rats were anesthetized with $2 \%$ isoflurane, and their ovaries were removed bilaterally. Rats underwent a sham operation $(\mathrm{n}=12)$, by exposing ovaries without excision, or ovariectomy (OVX, $\mathrm{n}=36$ ), by ligating and excising the ovaries. After a 2-week acclimation period, the sham and normal diet groups were fed a normal (0.6\% Ca) diet (TD.97191), while the other groups were fed a low-Ca $(0.01 \%)$ diet (TD.95027). The animals were randomly divided into four groups (12 rats per group): (1) Sham (normal diet); (2) low-Ca (OVX + low-Ca); (3) normal diet (OVX + normal diet); and (4) NM $(\mathrm{OVX}+$ low-Ca $+50 \mathrm{mg} / \mathrm{kg} \mathrm{NM})$ (Table S1). The dietary supplement composition is shown in the Supplementary Material (Table S1). The food intake was monitored daily, and the rats were weighed once weekly. The rats were dosed $50 \mathrm{mg} \mathrm{NM} / \mathrm{kg}$ body weight via drinking water ad libitum. At the end of the 8-week feeding period, the rats were dissected. Blood samples were collected from the heart while the animal was lightly anaesthetized, and serum was separated by centrifugation $(848 \mathrm{~g}$ for $30 \mathrm{~min}$ ) and then stored at $-80{ }^{\circ} \mathrm{C}$ prior to the biochemical analyses. Tibial bones were dissected and stored at $-80^{\circ} \mathrm{C}$.

\subsection{Biochemical Analyses}

Serum alanine aminotransferase (ALT), aspartate aminotransferase (AST) levels, total cholesterol and the high-density lipoprotein (HDL)-cholesterol were measured using commercial kits (Asan Pharm Co. Ltd., Seoul, Korea). Tibial Ca content was measured as follows: Subsequent to the densitometry measurements, the tibias were ashed in a muffle furnace at $600{ }^{\circ} \mathrm{C}$ for $4 \mathrm{~h}$. The ash was weighed and then dissolved in $4 \mathrm{~N} \mathrm{HCl}$ prior to Ca determination by atomic absorption spectroscopy (Varian AA-20, Varian Analytical Instruments, Walnut Creek, USA) and phosphorus analysis by visible spectroscopy (Varian Cary One), using AOAC procedures.

\subsection{Bone Strength Test}

The breaking force of the tibia was measured using an A/WEG wedge fracture probe (Stable Micro Systems, Godalming, UK). The wedge was fractured by a downward motion $(3 \mathrm{~mm} / \mathrm{s})$ of a $30 \mathrm{~mm}$-wide steel blade. The maximum force $(\mathrm{N})$ applied to break the wedge was used to quantify bone firmness.

\subsection{Measurement of Tibial Bone Ca Content}

The Ca content of the tibias was quantified by inductively coupled plasma mass spectrometry (ICP-MS, HP-4500; Hewlett-Packard, Avondale, PA, USA), using a microwave digestion system (Multiwave 3000; Anton Paar, Graz, Austria). All tests were performed following AOAC procedures.

\subsection{Micro-Computerized Tomography (Micro-CT)}

Tibial morphometric parameters were measured in the distal tibia using a high-resolution cone-beam micro-CT system (Inveon PET; Siemens Medical Solutions, Knoxville, TN, USA). The bone surface area/bone volume (BSA/BV), bone volume/total volume (BV/TV), trabecular separation (Tb.Sp), trabecular thickness (Tb.Th), and trabecular number (Tb.N) were calculated from 3D measurements of the trabecular bone mass and its distribution. The cortical wall thickness (Ct.Th) was calculated from 3D measurements of cortical bone mass and its distribution, according to standard procedures. Scans were performed using $80 \mathrm{kV}$ of applied voltage with a $1 \mathrm{~mm}$ aluminum filter. All cross-sections contained $2048 \times 2048$ pixels, with an isotropic voxel size of $9.31 \mu \mathrm{m}$. Data analysis was conducted using the Inveon Acquisition Workplace software (Siemens). 


\subsection{Histological Evaluation}

The tibias were fixed in $10 \%$ neutral-buffered formalin for 2 days at $40{ }^{\circ} \mathrm{C}$. Decalcification was achieved by immersion in $10 \%$ ethylenediaminetetraacetic acid (EDTA, $\mathrm{pH} 7.4$ ), which was replaced daily for 20 days, with stirring, at room temperature. The bones were washed in tap water for $4 \mathrm{~h}$, the tibias were embedded in paraffin, and longitudinal $4 \mu \mathrm{m}$ sections were cut using a microtome. The sections were mounted, stained using hematoxylin and eosin (H\&E), and observed by light microscopy at a magnification of $100 \times$.

\subsection{Von Kossa Staining}

Formalin- and ethanol-fixed tibia samples were incubated with $1 \%$ silver nitrate. Then, tibia samples placed under UV light at $10 \mathrm{~min}$, rinsed in distilled water, and unreacted with $5 \%$ sodium thiosulfate for $5 \mathrm{~min}$. The samples were stained with $0.1 \%$ Nuclear Fast Red solution for $5 \mathrm{~min}$. Then, the samples were dehydrated with grade ethanol and mounted using DPX mounting medium.

\subsection{Reverse Transcriptase PCR (RT-PCR)}

Rat tibia RNA was isolated at the TRIzol soultion (Invitrogen, Carlsbad, CA, USA). Aliquots $(1 \mu \mathrm{g})$ of total RNA were reverse transcribed using SuperScript III Reverse Transcriptase (Invitrogen). The resultant cDNA was used to determine the tibial mRNA expression levels of BMP-2, cathepsin K, COL-1, osteocalcin, RANK, RUNX2, TRAP, and Wnt3a using Taq DNA polymerase (KAPA Biosystems, London, UK). Glyceraldehyde 3-phosphate dehydrogenase (GAPDH) was used as an internal control. The PCR primers used are listed in Table S2. The following thermocycling conditions were used: $95^{\circ} \mathrm{C}$ for $3 \mathrm{~min} ; 30-40$ cycles at $95^{\circ} \mathrm{C}$ for $30 \mathrm{~s}$ and $50-60^{\circ} \mathrm{C}$ for $30 \mathrm{~s}$ (the number of cycles and annealing temperatures were optimized for each primer pair); and $72{ }^{\circ} \mathrm{C}$ for $10 \mathrm{~min}$. The PCR products were separated by agarose (1.2\%)/ethidium bromide gel electrophoresis and photographed.

\subsection{Immunohistochemical Analysis}

Sections $(4 \mu \mathrm{m})$ of the decalcified and paraffin-embedded tibias were mounted onto 3-aminopropyltriethoxysilane (APES)-coated slides, deparaffinized in xylene, rehydrated using ethanol, and rinsed in PBS. Endogenous peroxidase activity was quenched by incubation in hydrogen peroxide $(0.3 \%)$ for $30 \mathrm{~min}$. The sections were incubated with goat serum $(10 \%)$ for $30 \mathrm{~min}$ before overnight incubation at $4{ }^{\circ} \mathrm{C}$ with the appropriate specific primary antibodies raised against BMP-2, RUNX2, Wnt3a, osteocalcin, or COL-1 (Abcam, Cambridge, MA, UK). The sections were then incubated with either biotinylated goat anti-rabbit IgG $(\mathrm{H}+\mathrm{L})$ horseradish peroxidase (HRP) conjugate (Zymax, San Francisco, CA, USA) or goat anti-mouse IgG (H+L) HRP conjugate (Zymax). The sections were then stained with 3,3'-diaminobenzidine (DAB Substrate Kit; Vector Laboratories, CA, USA) and counterstained with hematoxylin. Negative controls were incubated with normal goat IgG instead of the primary antibody. The specimens were examined using an Eclipse TS100 microscope (Nikon, Tokyo, Japan) at 200× magnification, and the images were analyzed using the Optiview 3.7 software (Korea Lab Tech, Sungnam, Korea).

\subsection{Western Blot Analyses}

Tibias were homogenized in RIPA lysis buffer including protease inhibitor (Roche, Mannheim, Germany) and centrifuged at $10,000 \times g$ for $10 \mathrm{~min}$ at $4{ }^{\circ} \mathrm{C}$. The total protein levels were determined using a Bio-Rad Protein Assay Kit. The proteins were subjected to SDS-PAGE and transferred onto Immobilon-P transfer membranes, which were blocked with bovine serum albumin $(5 \%)$ prior to incubation with specific primary antibodies raised against BMP-2, Wnt3a, RUNX2, or COL-1 (Abcam); p-SMAD 1/5/8 (Santa Cruz, Texas, USA); or p-ERK, p-p38, p-JNK, or $\beta$-actin (Cell Signaling Technology, Danvers, MA, USA). The membranes were then incubated with the appropriate secondary antibodies, either goat anti-rabbit IgG H\&L (HRP) (Abcam) or goat anti-mouse IgG H\&L (HRP) (Abcam). The antigen-antibody 
complexes were visualized using enhanced chemiluminescence. Densitometric analysis was performed using a C-DiGit Blot Scanner (Li-COR Biosciences, Lincoln, NE, USA).

\subsection{Statistical Analyses}

Data are presented as the mean \pm SD of triplicate experiments. Statistical analyses were conducted using the Statistical Package for the Social Sciences (SPSS) version 18.0 (SPSS Inc., Chicago, IL, USA). The groups were compared using one-way ANOVA followed by Duncan's multiple range tests, and $p$-values $<0.05$ were considered statistically significant.

\section{Results}

\subsection{Characteristics of Montmorillonite}

Figure 1A shows the XRD pattern of the purified montmorillonite. The primary XRD peaks were around $2 \theta=5.6^{\circ}, 19.8$, and $34.9^{\circ}$. These peaks confirmed a typical montmorillonite in the dioctahedral montmorillonite group $[1,37]$. The distance between the two-unit montmorillonite sheets from the powder sample was measured by the PDXL software. The calculated distance is $15.6 \AA$, which agrees with previously reported results for Ca-type montmorillonites $[14,38,39]$. The shape of the montmorillonite is described in Figure 1B using an SEM image. The observed size range of the particles was approximately 1 to $7 \mu \mathrm{m}$. The irregular size and morphology of the sample appears to be due to aggregation of montmorillonite particles or inter-particle contact during oven drying at $353 \mathrm{~K}$. As determined by EDS and shown in Figure 1C, the quality and quantity index ratios of the peak areas were obtained from the EDS fingerprint spectra. The predominant elements in the montmorillonite sample were $\mathrm{Si}, \mathrm{Al}, \mathrm{Fe}, \mathrm{Mg}$, and $\mathrm{Ca}$, in varying levels. The montmorillonite had high $\mathrm{Ca}(3.66 \mathrm{wt} \%$ ) and low $\mathrm{Na}(0.80 \mathrm{wt} \%)$ content. The particle size distribution (PSD) of NM is summarized in Figure 1D. The sample PSD ranged from 65 to $338 \mathrm{~nm}$. The size analysis results showed a bimodal distribution that centered at 87 and $264 \mathrm{~nm}$, with an average of $179 \mathrm{~nm}$. This bimodal PSD pattern is similar to the NM PSD graph described previously [40,41]. The average size is smaller than other NMs reported, which have average bimodal sizes of $280 \mathrm{~nm}$ in diameter [42]. In conclusion, the results confirmed that the sample was, indeed, a natural Ca-type NM.

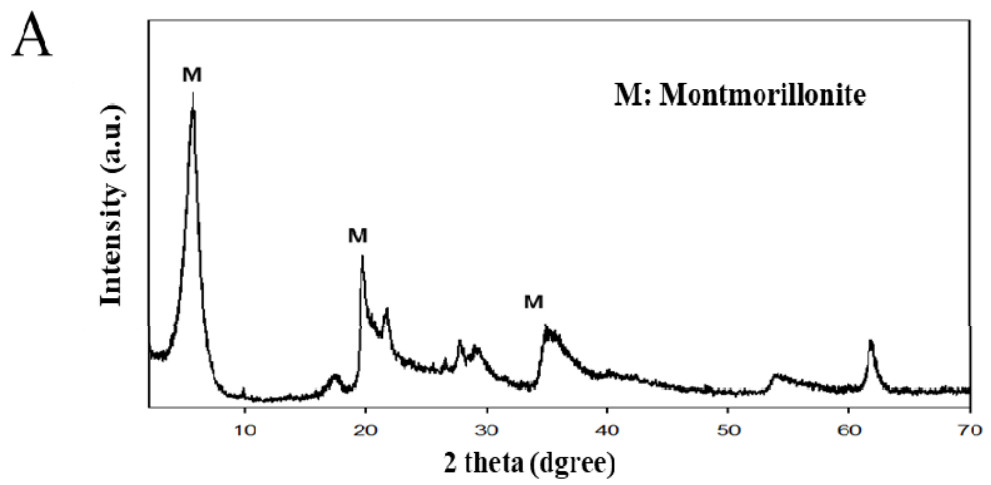

Figure 1. Cont. 
B

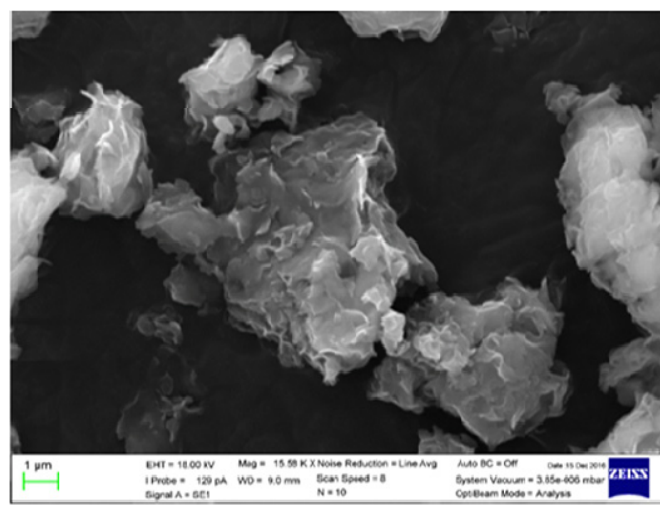

C

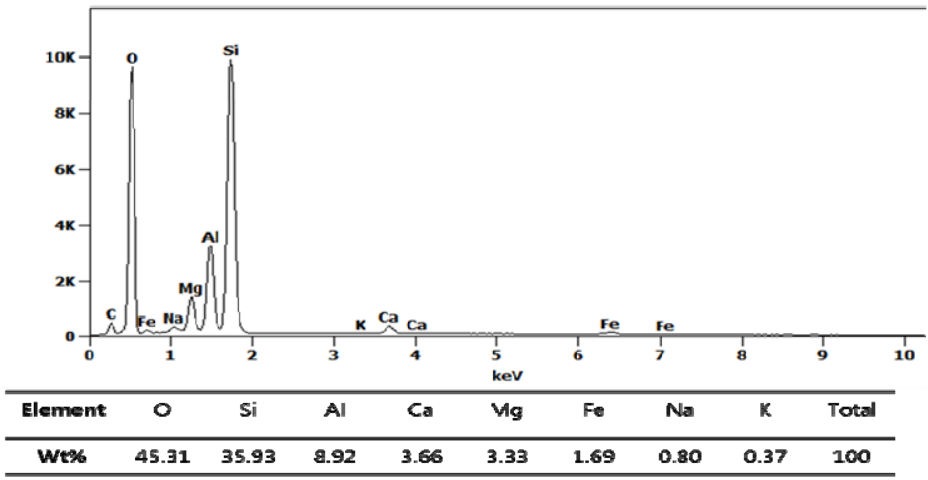

$\mathrm{D}$

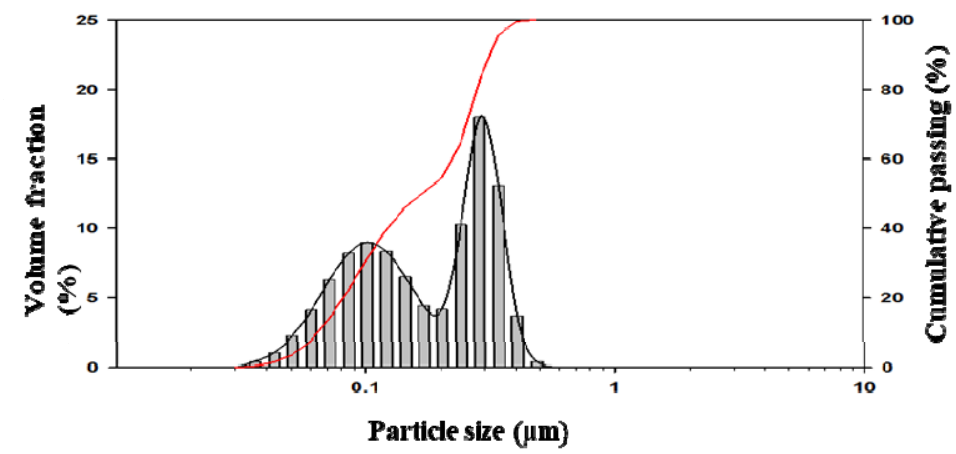

Figure 1. (A) X-ray powder diffraction (XRD) pattern, (B) scanning electron microscopy (SEM) image (magnified 15.58K-fold), (C) energy-dispersive X-ray spectroscopy (EDS) spectrum of purified montmorillonite, and (D) particle-size distribution of the nano-montmorillonite suspension.

\subsection{NM Activates Alp and Mineralization in Osteoblasts}

NM did not exhibit any significant effect on cell viability for $72 \mathrm{~h}$ at the concentrations used in this study. Osteoblasts produce ALP in association with mineralization and matrix maturation [43]. As shown in Figure 2A, the NM-treated group showed significantly enhanced ALP activity, and the effect was dose-dependent from $250-1000 \mu \mathrm{g} / \mathrm{mL}$ (Figure 2A) $(p<0.05)$. The degree of mineralization in the NM-treated group was observed using alizarin red $\mathrm{S}$ counterstaining and quantified by $\mathrm{Ca}$ deposition analysis. The matrix mineralization of NM treated group (350\%) was the higher than control group at $500 \mu \mathrm{g} / \mathrm{mL}$ concentration. The mineralization did not show significant in concentrations of NM (Figure 2B). The NM-treated cells demonstrated redder color than the control cells, indicating the promotion of bone mineralization (Figure 2C). Thus, NM effectively enhanced osteoblast maturation, by increasing bone mineralization. 

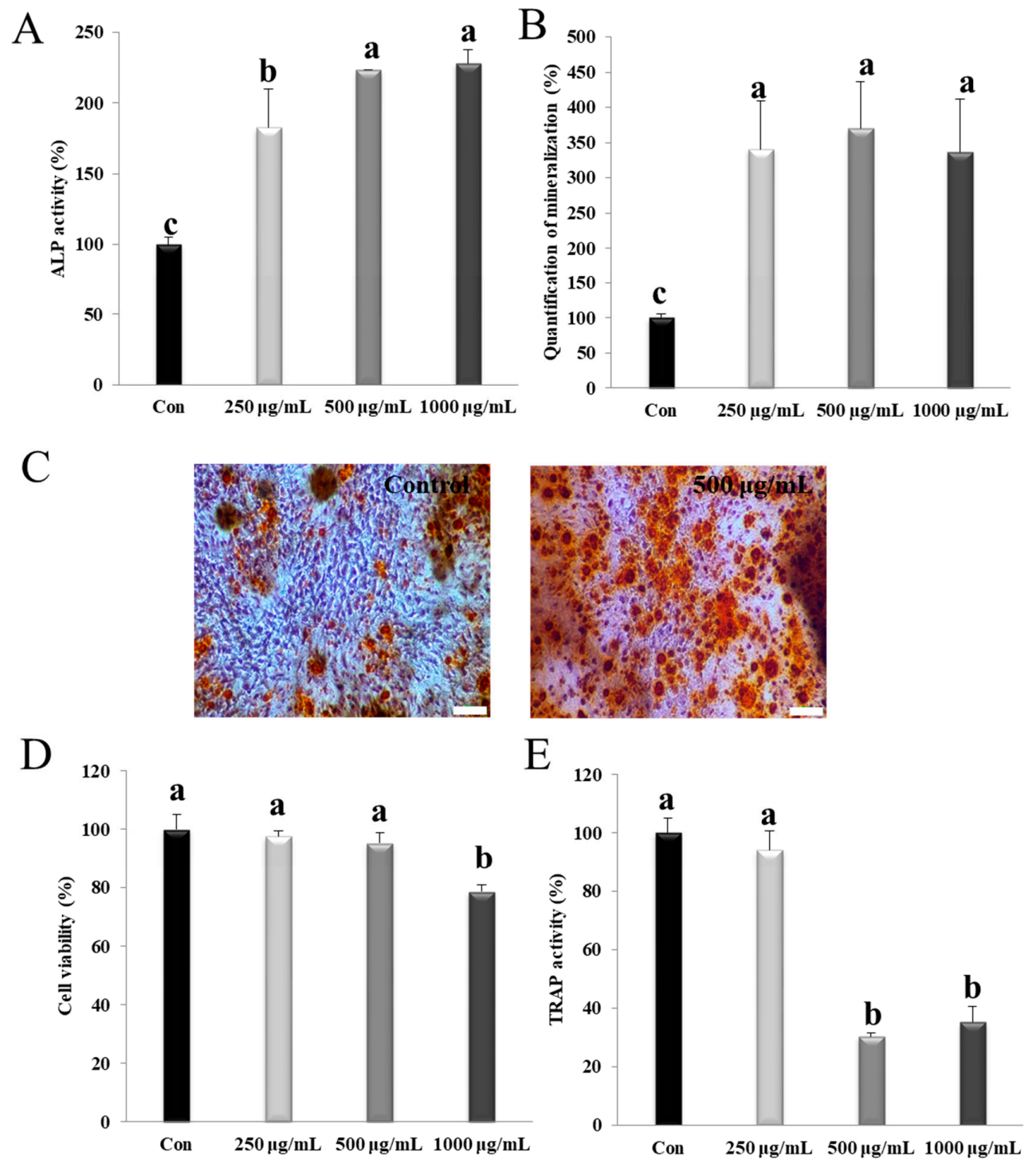

F
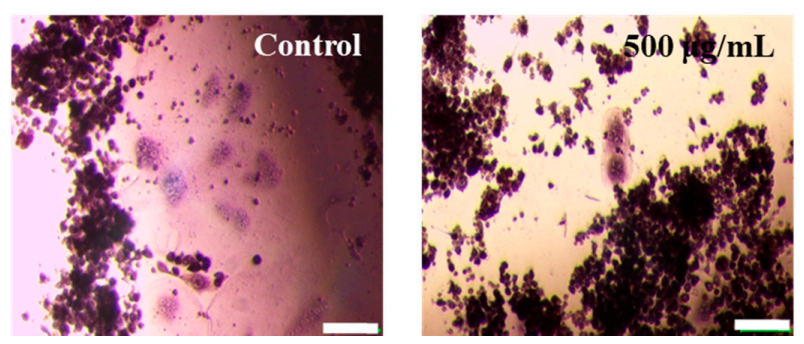

Figure 2. Effect of nano-montmorillonite (NM) on alkaline phosphatase (ALP) activity and mineralization during differentiation in MG-63 cells. (A) Cells were treated with the indicated $\mathrm{NM}$ concentrations for $24 \mathrm{~h}$ before measuring the cell viability and for $96 \mathrm{~h}$ before measuring the ALP activity, as described in Materials and Methods. Scale bar: $20 \mu \mathrm{m}$. (B,C) Cells were treated as indicated for 14 days before staining the mineralized matrix with alizarin red $\mathrm{S}$ and quantifying the mineralization as described in Materials and Methods. Effect of NM on RAW 264.7 cell viability (D), tartrate-resistant acid phosphatase (TRAP) activity (E), and TRAP staining (F, control and NM $500 \mu \mathrm{g} / \mathrm{mL}$ ) during differentiation. Scale bar: $20 \mu \mathrm{m}$. Results are expressed as the mean $\pm \mathrm{SD}$. Values not sharing a common superscript $(\mathbf{a}-\mathbf{c})$ differed significantly (Duncan's multiple range test) $(p<0.05)$. 


\subsection{NM Suppresses Osteoclast Differentiation in Osteoclast Precursor Cells}

In prior to evaluate inhibitory effect of NM in osteoclast differentiation, cytotoxicity assay was performed in vitro. Thus, the cell was treated with three different concentrations of NM (250, 500, and $1000 \mu \mathrm{g} / \mathrm{mL}$ ) to determine the concentrations that inhibited osteoclast precursor cell proliferation. NM concentration under $500 \mu \mathrm{g} / \mathrm{mL}$ did not show significant cytotoxicity in osteoclast precursor cells (Figure 2D). As shown in Figure 2E, the exposure to $1000 \mu \mathrm{g} / \mathrm{mL}$ NM significantly inhibited TRAP activity in multinucleated TRAP-positive RAW 264.7 cells. NM suppressed TRAP activity to 30.4\% of the control value. As shown in Figure 2F, NM-treated RAW 264.7 cells exhibited greatly repressed TRAP-positive multinucleated cells, compared to that in the NM-untreated cells. Our results suggest that osteoclastogenesis was significantly decreased in RAW 264.7 cells treated to NM. This indicates that NM has the potential to suppress bone resorption during osteoporosis.

\subsection{NM Enhances Expression of Osteoblast Differentiation Marker Genes via P38}

Figure $3 \mathrm{~A}$ shows the mRNA expression levels of osteoblast differentiation-associated genes in MG-63 cells with NM treated for 3 days. Four genes involved in bone metabolism were analyzed: RUNX2, osteocalcin, BMP-2, and collagenase-1 (COL-1). The mRNA expression level of BMP-2 and RUNX2 increased by 1.53- and 1.15-fold in the NM-treated group compared to that in the control cell. In addition, the osteocalcin and COL-1 mRNA expression levels were 1.45- and 1.29-fold higher in the NM-treated cell than in the control group. As shown in Figure 3B, we estimated the effect of NM treated group on the bone metabolism indicators RUNX2, BMP-2, COL-1, Wnt3a and p-SMAD 1/5/8 in MG-63 cells. The protein expression levels were significantly increased for RUNX2, BMP-2, COL-1, Wnt3a and p-SMAD 1/5/8 in the NM-treated cells compared to the control cells. The BMP-2 and Wnt3a protein expression levels increased by 9.39- and 2.72-fold, respectively, in the NM-treated cells compared to the control cells. In addition, the p-SMAD 1/5/8, RUNX2, and COL-1 protein expression levels in the NM-treated group increased by 5.74-, 1.31-, and 3.36-fold, respectively, compared to that in the control cells. These findings suggested that BMP2-dependent p-SMAD 1/5/8/RUNX2/osteocalcin/COL-1 signaling was increased in cultured MG-63 cells exposed to NM, leading to osteoblast differentiation.

As shown in Figure 3C, the activation level of p38 was significantly increased (9.57-fold) in the cells treated with NM compared to that in the control cells. The NM-treated cells showed significantly reduced protein levels of p-AKT, p-JNK, and p-ERK compared to the control cells. These data suggested that p38 signaling was activated in cells treated with NM.

\subsection{NM Inhibits Osteoclast Formation Genes}

Expression level of cathepsin K, TRAP, and RANKL were significantly decreased in the NM-treated group compared to the control group (Figure 3D). In addition, the TRAP expression level in the NM-treated cells was 4.78-fold lower than those in the control group (Figure 3D). These results suggested that NM suppressed mRNA expression level of osteoclastogenesis related genes in vitro.

\subsection{Food Efficiency Ratio}

The body weight gain, food intake, and food efficiency ratio did not show significant differences among the experimental groups, as shown in the Supplementary Material (Table S3).

\subsection{NM Improves High-Density Lipoprotein (HDL)-Cholesterol Lipid Metabolism and Prevents Atherosclerosis}

There were no significant differences in the serum levels of ALT or AST between the different study groups, as shown in the Supplementary Material (Figure S1A). Total serum cholesterol was significantly higher in the NM-treated rats than in the other groups (Figure S1B). Especially, the level of HDL-cholesterol in the NM group increased by 19.7\% compared to that in the low-Ca group. Also, HDL-cholesterol in the NM group was higher than in the normal diet group. These data imply that NM improves lipid metabolism as evidenced by the increased HDL-cholesterol level. The serum estrogen 
concentration reduced in the low-Ca group compared to the other groups (Figure S1C). Interestingly, the NM group showed an increased serum estrogen level (1.38-fold) compared to the low-Ca group.
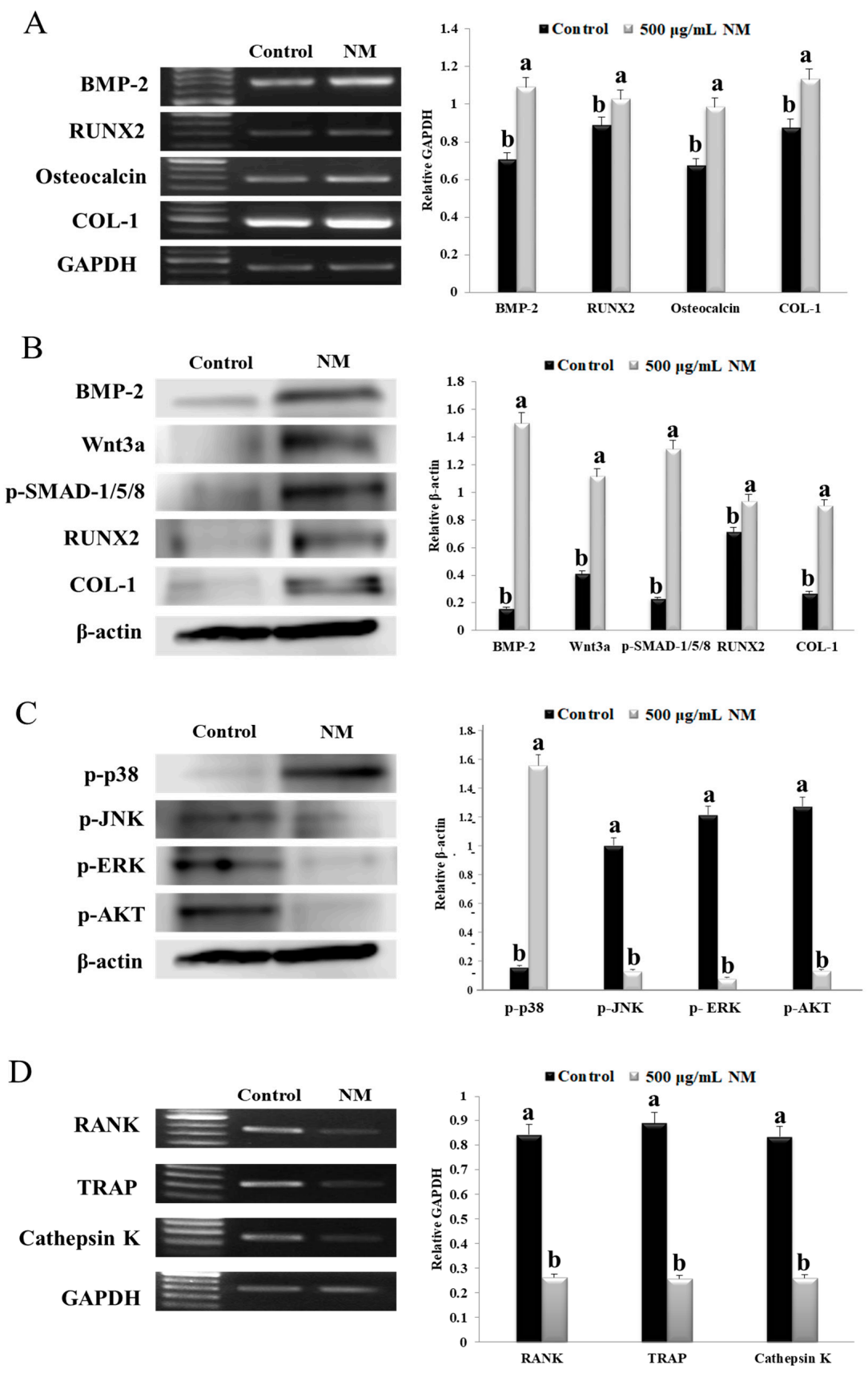

Figure 3. MG-63 osteoblast and RAW 264.7 osteoclast mRNA and protein expression levels of molecules involved in bone metabolism and signaling. (A,B) The cells were differentiated for 4 days in differentiation medium prior to reverse transcription PCR (RT-PCR) analysis of bone morphogenetic protein-2 (BMP-2), runt related transcription factor-2 (RUNX2), osteocalcin, and type 1 collagen (COL-1); mRNA levels and protein levels. (C) Levels of phosphorylated extracellular signal-regulated kinase (p-ERK), p-p38, phosphorylated serine/threonine kinase (p-AKT), and phosphorylated c-Jun $\mathrm{N}$-terminal kinase (p-JNK) were determined by Western blot. (D) mRNA expression of receptor activator of nuclear factor kappa-B (RANK), tartrate resistant acid phosphatase (TRAP), and cathepsin $\mathrm{K}$. The relative expression was quantified using Image J and calculated relative to glyceraldehyde 3-phosphate dehydrogenase (GAPDH) and $\beta$-actin. Results are expressed as the mean $\pm \mathrm{SD}$. Values not sharing a common superscript $(\mathbf{a}, \mathbf{b})$ differed significantly (Duncan's multiple range test) $(p<0.05)$. 


\subsection{NM Increases Tibial Ca Content and Bone Strength}

To investigate the effects of NM-containing diets on bone strength, we analyzed a breaking force test using a texture analyzer (Figure 4A). The breaking force required in the NM group was 17.23\% higher than in the low-Ca group (Figure 4B). In addition, the breaking force of the NM group (35.02 N) increased compared to the normal diet group $(27.61 \mathrm{~N})$. Tibial Ca levels were higher in the normal diet group than in the NM group (Figure 4C). However, the NM group had greatly increased Ca levels than the low-Ca group. The NM group had 33.7\% more tibial Ca than the low-Ca group, which showed no significant difference from the sham group (Figure 4D). Thus, the NM diet increased the tibial bone strength and the concentration of $\mathrm{Ca}$ in bone, compared to the low-Ca group.

A

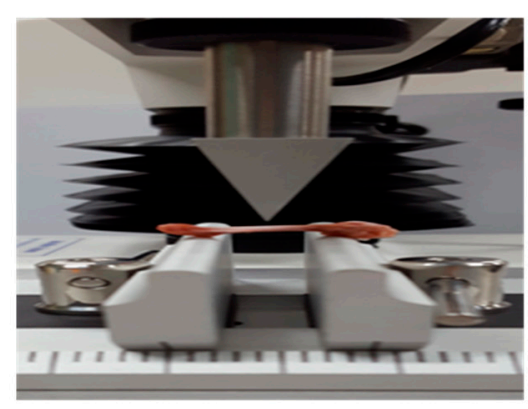

B

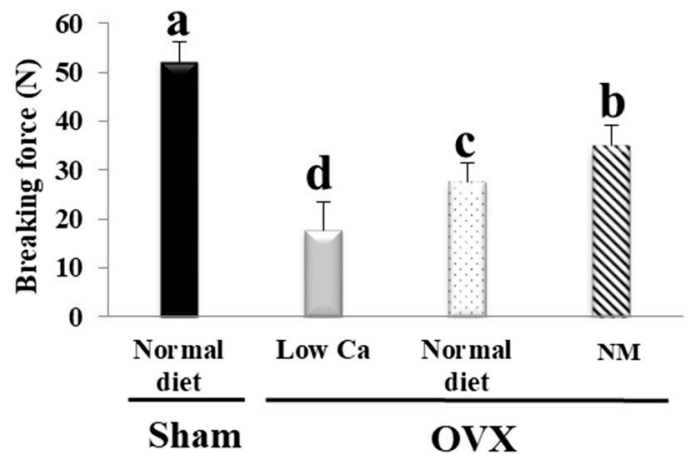

$\mathcal{C}$

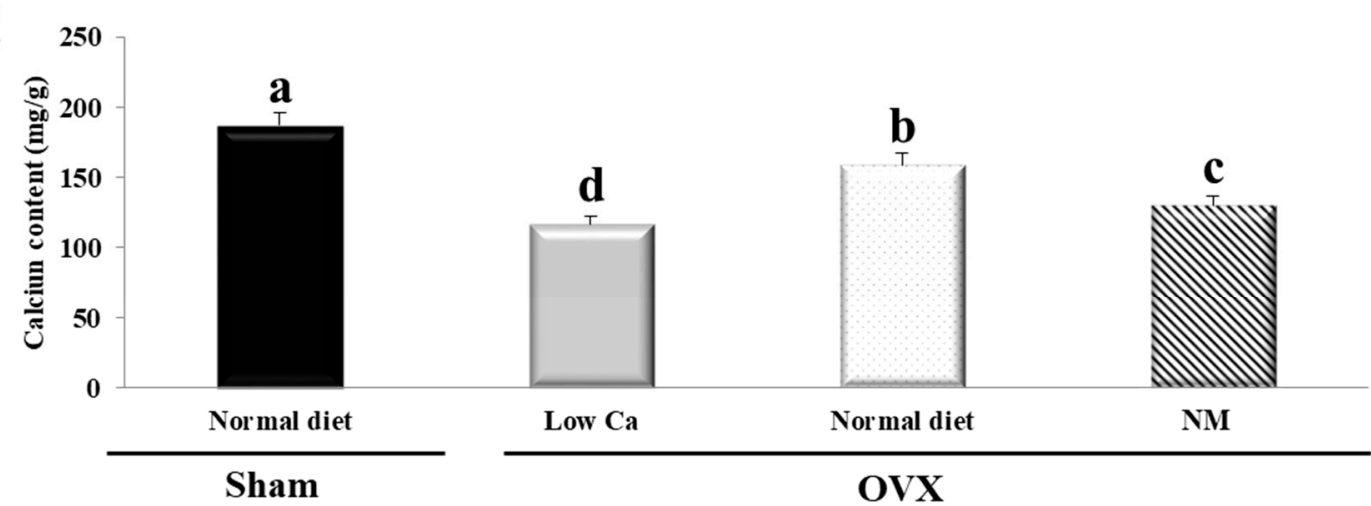

D

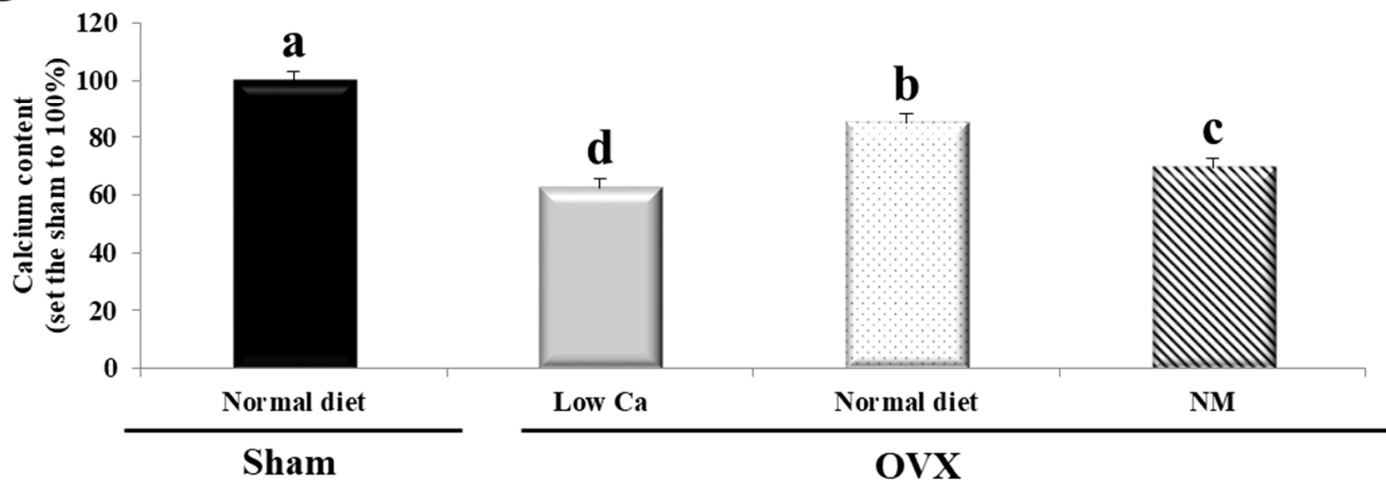

Figure 4. Breaking force graph for the rat tibia. (A) Details of the breaking force measurement by texture analysis. (B) Breaking force required for rat tibias. (C) Tibial Ca levels in the indicated rats. (D) The value of the tibial Ca levels when sham was set to $100 \%$. Results are expressed as the mean \pm $\mathrm{SD}$. Values not sharing a common superscript $(\mathbf{a}-\mathbf{c})$ differed significantly (Duncan's multiple range test) $(p<0.05)$. 


\subsection{NM Improves BMD and Bone Microarchitecture}

Ex vivo micro-CT was performed 8 weeks after OVX or sham surgery for all animals in the study; the tibial architecture was evaluated using the maximum intensity projection images (Figure 5A). Our study analyzed the trabecular and cortical compartments of the tibia, using measurements and images of longitudinal and cross-sections that indicated the location slab of the trabeculae. After 8 weeks, rats fed a low-Ca diet showed an overall loss of the tibia, indicated by an increase in bone spacing and decrease in the bone mass, bone marrow, and thickness (Figure 5A). The longitudinal sections of the tibias from the low-Ca group show central spaces in the trabeculae (Figure 5A). The low-Ca group shows large spaces within the marrow in the upper and lower tibial cross-sections. In contrast, the longitudinal and cross-sectional analyses of the sham and NM groups observed that the bone marrow space was more occupied in the NM group than in the low-Ca group. The sham and NM groups distributed bone structures in a relatively uniform fashion, forming a well-connected network (Figure 5A).

Micro-CT analysis was used to calculate trabecular BMD, cortical BMD, BV/TV, BSA/BV, Tb.Th, Tb.N, Tb.Sp, and Ct.Th (Figure 5B). The low-Ca feed decreased trabecular BMD, cortical BMD, BV/TV, Tb.Th, and Ct.Th. However, the low-Ca feed increased BSA/BV, Tb.N, and Tb.Sp. In addition, NM increased trabecular BMD, cortical BMD, BV/TV, and Ct.Th by $7.56 \%, 15.15 \%, 10.80 \%$, and $10.81 \%$, respectively, compared to the low-Ca group. Furthermore, cortical BMD, BV/TV, and Ct.Th increased in the NM group, compared to the normal diet group. Tb.N and Tb.Sp decreased by $11.98 \%$ and $39.36 \%$, respectively, compared to the low-Ca group. However, BSA/BV and Tb.Th were not significantly different in the low-Ca and NM groups (Figure 5B). These data indicated that dietary supplementation with NM attenuated the loss in integrity of the trabeculae in OVX rats. These effects were confirmed by histological analyses using H\&E staining.

\subsection{NM Increases Trabecular Connections}

To gain insight into the mechanism of the enhanced bone formation in OVX rats, we performed histomorphometric analysis. The bone trabeculae of the rats in the low-Ca group were arranged randomly, were thinner, or had disappeared altogether, while the remaining connections were incomplete (Figure 6A). Trabecular continuity was not optimal, and there were apparent signs of resorption. However, the arrangement of the trabeculae in the NM group showed that a greater number connected to form a bone network, and in a more orderly arrangement than what was observed in the low-Ca group (Figure 6A). The analysis indicated that osteoid formation improved with NM supplementation, compared to the low-Ca group. By von Kossa staining, differences might not be observed between the sham, normal diet, and NM groups.

We showed by H\&E staining that the osteoclast activity was increased in the endochondral zone and epiphysis of the rates in the low-Ca group, as evidenced by the increased staining of the osteoclast-specific marker TRAP (Figure 6A). These findings indicate that NM dietary supplementation improves trabecular structure and continuity.

Immunohistochemical staining was conducted to detect the osteogenesis-related proteins BMP-2, RUNX2, Wnt3a, osteocalcin, and COL-1. For BMP-2, the connective bone tissue surrounding the trabeculae showed mild staining in the low-Ca group, and a small trend towards increased staining was observed in the sham and NM groups (Figure 6B). For Wnt3a, the low-Ca group showed a mild staining pattern in the bone tissue surrounding the trabeculae, while intense staining was showed in the NM group. Additionally, the NM group showed moderate RUNX2 staining in the connective tissue surrounding the trabeculae. The low-Ca group showed mild staining for osteocalcin and COL-1, while the sham and NM groups showed more intense staining. Furthermore, Wnt3a, RUNX2, and COL-1 staining was more intense in the NM group compared to the normal diet group. These results demonstrated that NM supplementation increased the bone levels of the osteogenesis-related BMP-2, RUNX2, Wnt3a, osteocalcin, and COL-1 proteins. 
A

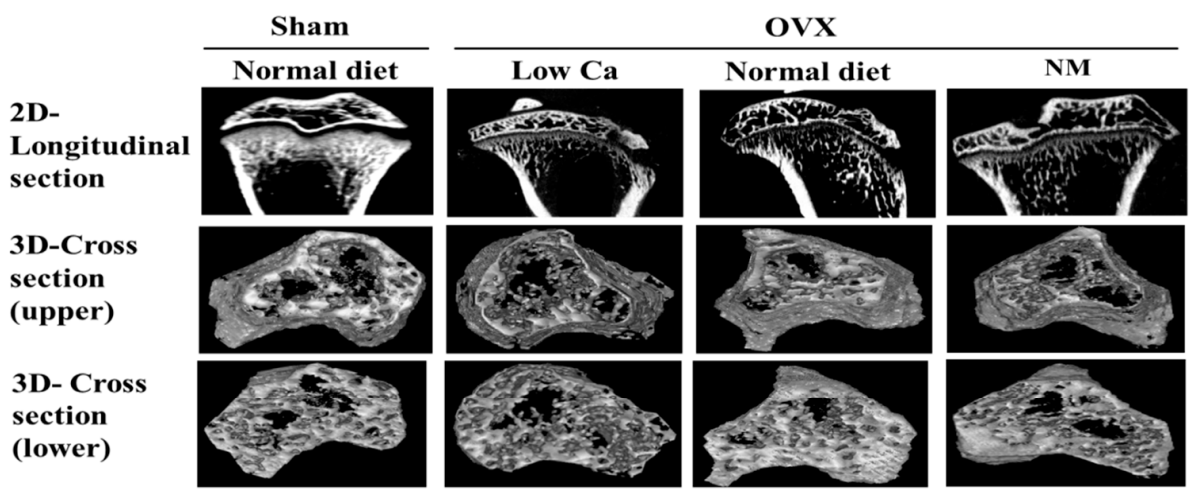

B
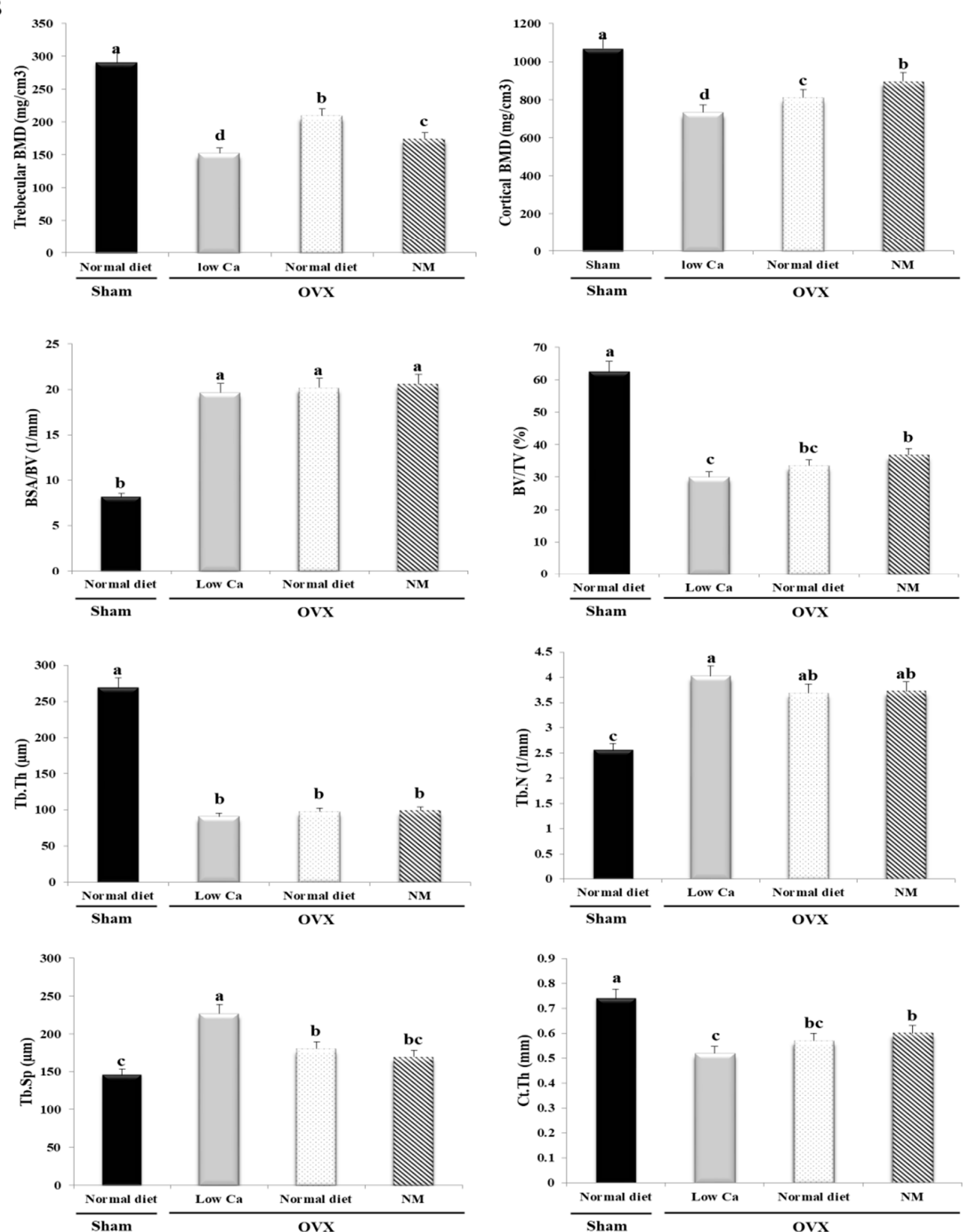

Figure 5. Tibial bone microstructure of ovariectomized (OVX) rats. (A) Longitudinal and cross-sections of trabeculae. (B) Trabecular bone and cortical bone analysis. Each value is expressed as the mean \pm SD. Values not sharing a common superscript (a-c) differed significantly (Duncan's multiple range test) $(p<0.05)$. 
A

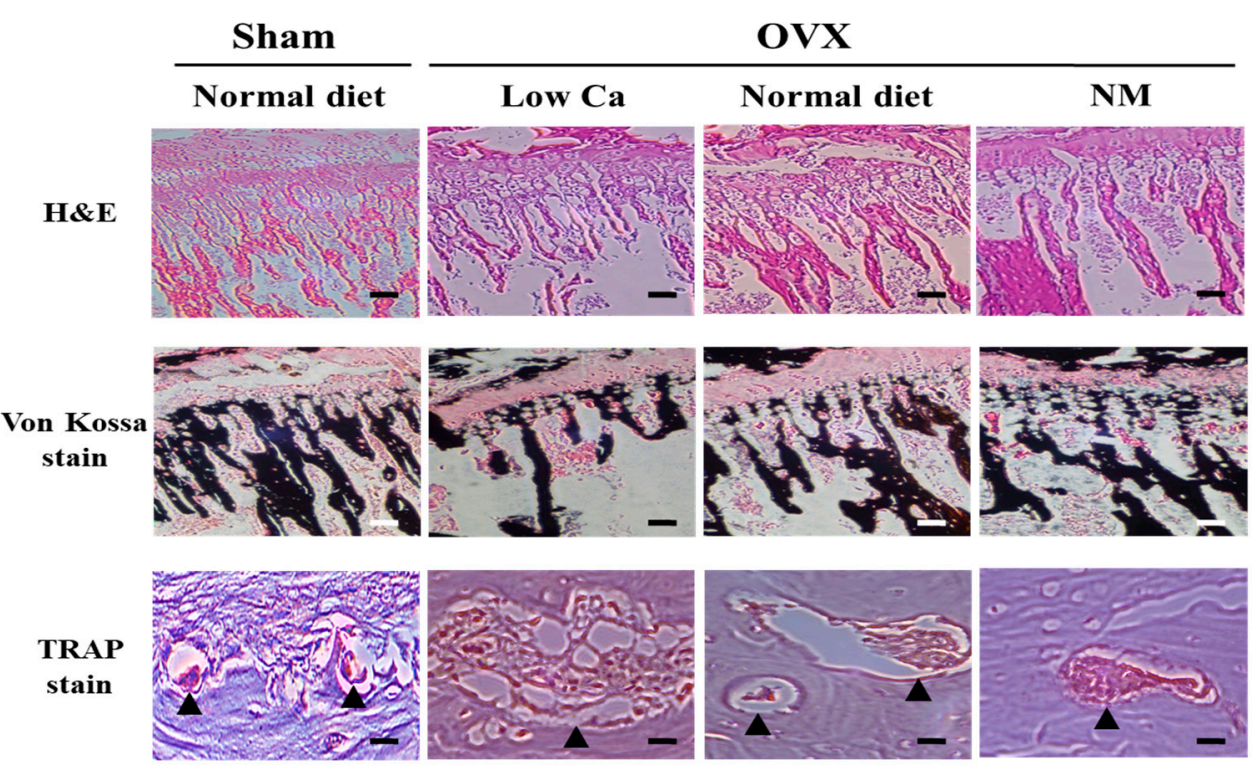

B

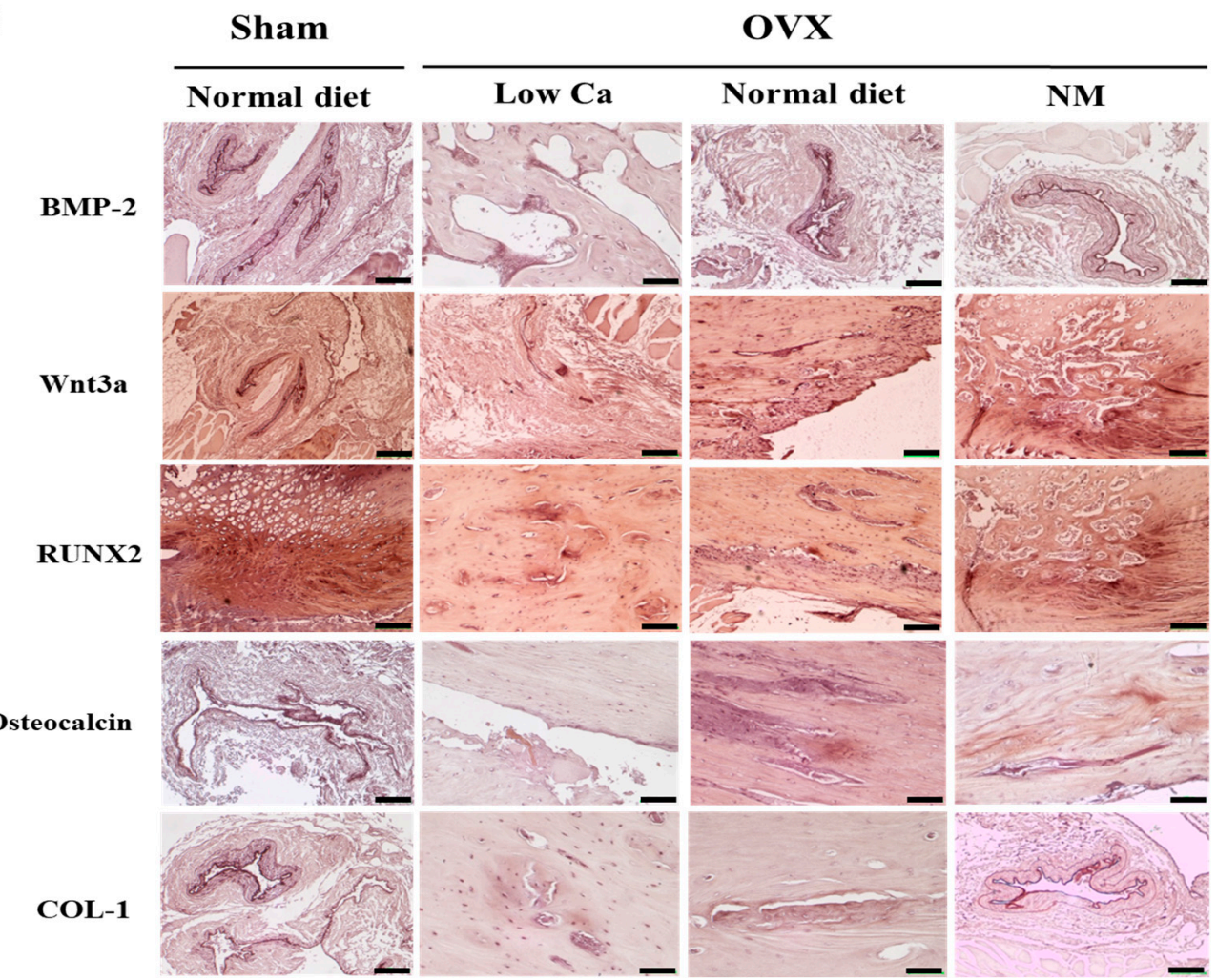

Figure 6. Histomorphology of the tibia of ovariectomized (OVX) rats. (A) Hematoxylin and Eosin (H\&E) stain, von Kossa stain, and tartrate-resistant acid phosphatase (TRAP) stain of the tibia. Black triangles indicate osteoclasts. Scale bar: $20 \mu \mathrm{m}$ (B) Immunohistochemical staining image of bone morphogenetic protein-2 (BMP-2), Wnt family member 3a (Wnt3a), runt-related transcription factor-2 (RUNX2), osteocalcin, and type 1 collagen (COL-1) in OVX rats. Scale bar: $100 \mu \mathrm{m}$.

\subsection{NM Promotes in Vivo mRNA and Protein Expression of Genes Involved in Osteoblastogenesis}

The tibial mRNA and protein expression levels are shown in Figure 7A,B. The mRNA and protein levels of the bone metabolism indicators BMP-2, Wnt3a, RUNX2, osteocalcin, and COL-1, were significantly upregulated in the NM group compared to the low-Ca group. In the NM group, the BMP-2 
and Wnt3a mRNA levels were 1.84- and 2.01-fold higher, respectively, than in the low-Ca group. Also, the mRNA levels of RUNX2, osteocalcin, and COL-1 in the NM group increased by 2.08-, 2.19-, and 1.71-fold, respectively, compared to the low-Ca group. Furthermore, the NM group significantly increased the expression of RUNX2, osteocalcin, and COL-1. The increased expression of RUNX2, osteocalcin, and COL-1 in the NM group was significantly higher than in the normal diet group. These results suggested that NM promoted mRNA expression of genes involved in osteoblastogenesis in vivo. The increased protein expression of BMP2 (28.20-fold) and Wnt3a (4.17-fold) in the NM group was significantly higher than in the low-Ca group. In addition, the expression of BMP-2 increased by 3.57-fold in the NM group compared to the normal diet group. The protein expression of p-SMAD 1/5/8 and RUNX2 in the NM group increased by 3.32- and 3.76-fold, respectively, compared to the low-Ca group. These findings suggested that BMP-2-dependent p-SMAD 1/5/8/RUNX2/osteocalcin/COL-1 signaling was activated in OVX rats exposed to NM, which induced osteoblast differentiation.

\subsection{NM Promotes in Vivo Osteoclastogenesis Related with the mRNA Expression of Genes}

We investigated the changes in mRNA expression level of cathepsin K, TRAP, and RANK in the OVX rat model. As shown in Figure 7C, the mRNA expression of cathepsin K, TRAP, and RANK in the low-Ca group were significantly increased compared to that in sham group. In the NM diet group, the TRAP mRNA expression was dramatically decreased (24.63-fold) compared to the low-Ca group. In addition, cathepsin K mRNA expression level in the NM group was significantly reduced (15.62-fold) compared to that in low-Ca group. Furthermore, the level of RANK mRNA expression was 3.45-fold lower in the NM group than in the low-Ca group. In particular, the cathepsin K, TRAP, and RANK mRNA expression levels in the NM group were downregulated compared to the normal diet group. These results suggested that the NM diet reduced the expression of genes involved in osteoclastogenesis.

3.13. NM Promotes in Vivo Expression of Phosphorylated Mitogen-Activated Protein Kinases (MAPKs) JNK, ERK, and P38

Mitogen-activated protein kinase (MAPK) signaling is important for the regulation of osteoblast differentiation and maturation [44]. In Figure 7D, we evaluated the effects of the NM diet on the activation of MAPK signaling, including the expression levels of p-p38, p-JNK, and p-ERK for the regulation of osteoblast differentiation. The activation of p-p38, p-JNK, and p-ERK in the low-Ca group was significantly decreased compared to that in the sham group. However, the p-p38, p-JNK, and p-ERK levels in the NM diet group increased by 4.08-, 3.57-, and 3.68-fold, respectively, compared to the low-Ca group. Also, p-ERK and p-JNK expression increased in the NM group (1.26- and 1.32-fold, respectively) compared the normal diet group. Thus, our results suggest that the NM diet activate osteoblast differentiation and suppress osteoclast differentiation via the activation of MAPK signaling pathways. 
A

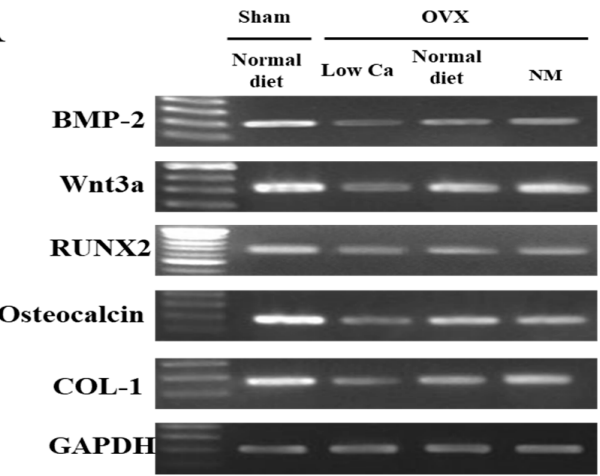

B

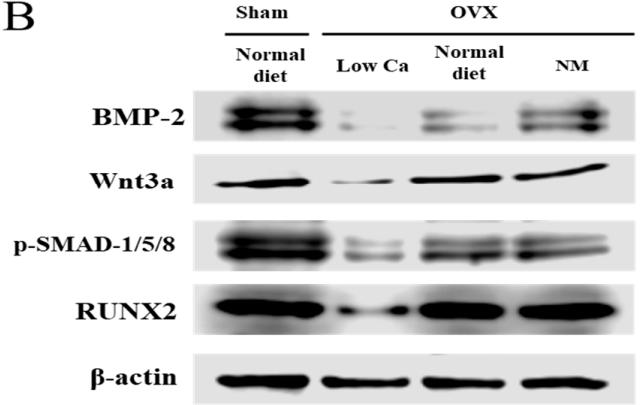

$\mathrm{C}$

Cathepsin K

RANK

GAPDH
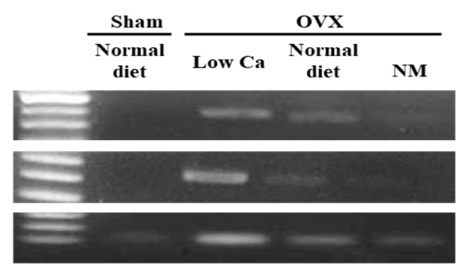

$\mathrm{D}$

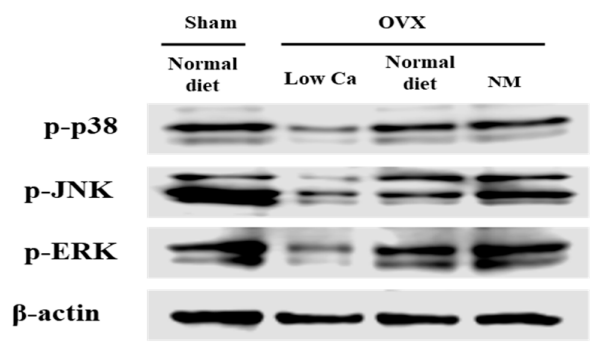

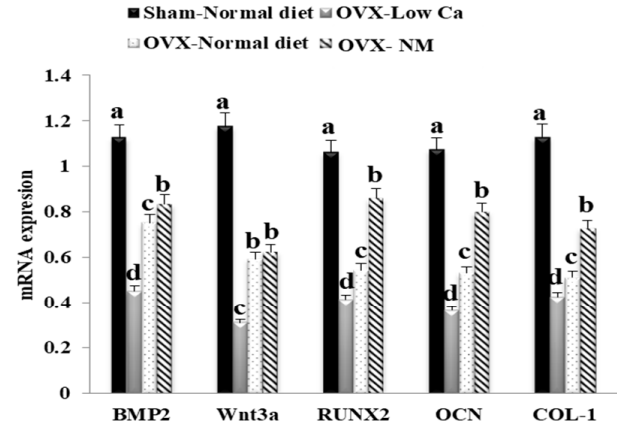
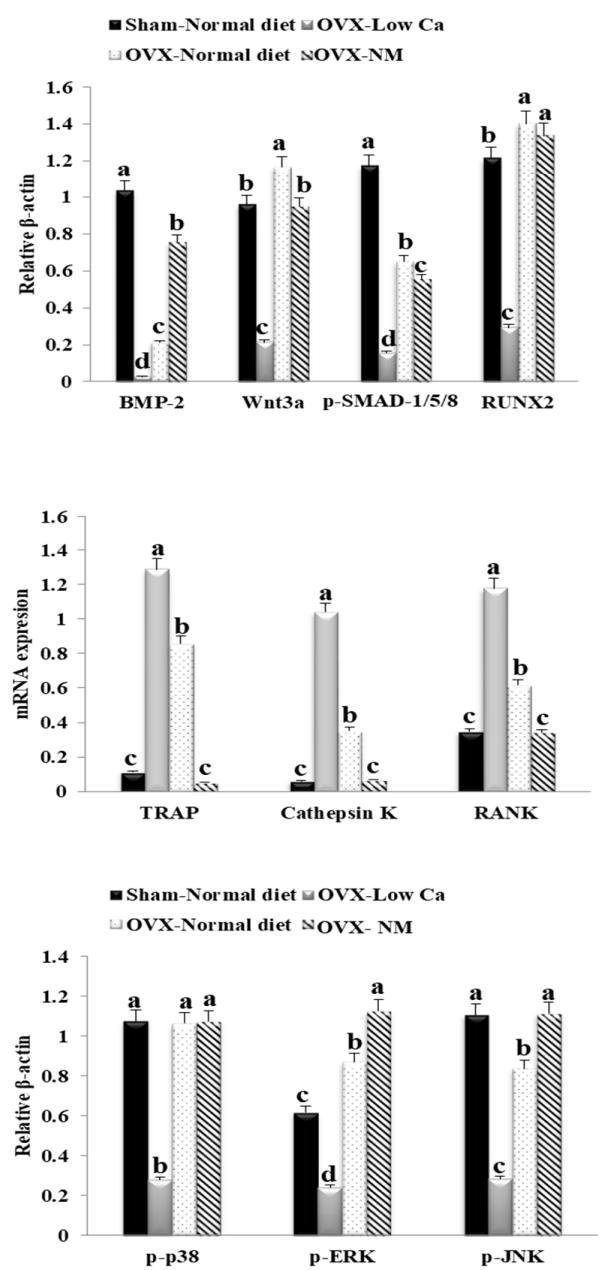

Figure 7. In vivo gene expression and histomorphology of the tibia of ovariectomized (OVX) rats. (A) mRNA expression levels of osteoblast differentiation factors: bone morphogenetic protein-2 (BMP-2), Wnt family member 3a (Wnt3a), runt-related transcription factor-2 (RUNX2), osteocalcin, and type-1 collagen (COL-1). (B) Protein expression levels of osteoblast differentiation factors: BMP-2, Wnt3a, phosphorylated small mothers against decapentaplegic homolog 1/5/8 (p-SMAD 1/5/8), and RUNX2. (C) Expression levels of phosphorylated extracellular signal-regulated kinase (p-ERK), p-p38, phosphorylated serine/threonine kinase (p-AKT), and phosphorylated c-Jun N-terminal kinase (p-JNK). (D) mRNA expression levels of receptor activator of nuclear factor kappa-B (RANK), tartrate resistant acid phosphatase (TRAP), and cathepsin $\mathrm{K}$ in vivo. Each value is expressed as the mean $\pm \mathrm{SD}$. Values not sharing a common superscript (a-d) differed significantly (Duncan's multiple range test) $(p<0.05)$. 


\section{Discussion}

Recently, several studies have showed intrinsic bone formation effect of certain clay in vitro in the bone marrow and adipose-derived stromal cell cultures, when dispersed in biomaterials or applied directly to cells as a culture supplement [45]. Our studies appreciated whether NM inhibits osteoporosis in the OVX rats. The present study is reported the first time that an NM suspension enhanced osteoblast proliferation, mineralization, and osteogenic related gene. Also, our results suggest that NM shows novel biomaterial properties, with optimal chemical composition, and regulates bone formation or resorption by modulating osteoblasts and osteoclasts during osteoporosis.

$\mathrm{NM}$ is composed of $3.66 \mathrm{wt} \% \mathrm{Ca}$ and has a size of $179 \mathrm{~nm}$ in diameter. The NM-supplemented group showed a 33.7\% increase in the tibial Ca content, compared to rats in the low-Ca group. Moreover, the breaking force required in the NM group was 33.2\% higher than in the low-Ca group. In addition, these results agree with those reported by Nordin et al., who showed that OVX rats had increased renal Ca loss; this could contribute to OVX-induced osteoporosis [46]. Our study showed that NM treatment of OVX rats fed a low-Ca diet decreased induction of osteoporosis. Generally, bone strength reflects bone quality. Bone quality parameters include bone microarchitecture, damage accumulation, and bone mineralization [47]. In our study, the NM suspension significantly interacted with the bone metabolism. These results showed that there is a possibility that the effects of NM were mainly mediated by supplementation of a natural Ca-type NM.

Our micro-CT results showed that the upper and lower cross-sections of the tibia had few trabeculae in the marrow region in the low-Ca group. However, in similar sections from the sham and NM treated groups, the bone marrow space was filled with relatively uniform plate-like trabecular structures that formed a well-connected bone structure (Figure 5A). The observed increase in BMD, cortical BMD, BV/TV, and Ct.Th, and the suppression in Tb.N and Tb.Sp, showed an increased overall bone strength and tibial trabecular and cortical bone density. The effects of OVX on bone are smaller in the cortical compartments than in the trabecular compartments [48]. Several reports have shown a reduction in BV/TV, Tb.Th, and Ct.Th and enhancement in BSA/BV, Tb.N, and Tb.Sp following OVX [34]. Our present findings in OVX rats are consistent with these observations. Moreover, we observed that $\mathrm{NM}$ affected the trabecular microarchitecture. Taken together, the micro-CT analysis indicated that NM attenuated OVX-induced osteoporosis. Bone regeneration is related to an induction of osteoblast cell proliferation, ALP activation, intracellular Ca deposition, mineralization and extracellular matrix formation [49-51]. As shown in Figure 2A, $250-1000 \mu \mathrm{g} / \mathrm{mL}$ of NM increased ALP activity in a dose dependent manner. Similar observations have been reported using osteoblasts grown on laponite nanoparticle gels, akermanite bioceramics, and titania; improvements in bone differentiation markers have also been reported, including accelerated mineralization and increased ALP activity in the bone matrix $[49,52,53]$.

The present study showed that NM treated group could increase ALP activity and gene expression of the osteogenic makers RUNX2, osteocalcin, BMP-2, COL-1, Wnt3a, and p-SMAD 1/5/8. These osteoblast-related markers are participated in bone regeneration, formation, and metabolism $[51,54,55]$. In addition, a previous study on the effects of genistein on osteoblast-associated metabolism proved that genes related to the BMP/SMAD signaling pathway showed the strongest enhancements in human bone marrow stromal cell (hBMSC) cultures [53]. This is similar to our results, and these findings prove that BMP/SMAD signaling is an important regulator of hBMSC differentiation into an osteoblast lineage, with BMP2-dependent SMAD5 signaling as a downstream pathway [55]. Also, the expression level of RUNX2 and its downstream gene osteocalcin increase in hBMSCs, indicating an important role of hBMCs in osteoblast differentiation [55,56]. In addition, recent studies reported that canonical Wnt signaling contributed to bone formation through enhancement of the RUNX2 transcription factor that drives osteoblast differentiation [57]. Consistent with these previous observations, our findings proved that BMP/RUNX2/SMAD signaling was of considerable importance for the enhancement of the osteoblast lineage observed in the presence of NM. 
Osteoclasts use to pivotal role in the bone resorption related with osteoporosis [58]. RANKL binds to RANK on preosteoclasts, stimulating their differentiation into osteoclasts [59]. Additionally, the RANKL-RANK interaction activates various osteoclastogenesis associated genes, such as cathepsin K and TRAP, via many downstream effectors [58]. Several studies showed that cathepsin K is an important osteoclast protease involved in bone matrix degradation [60]. Cathepsin K participates in osteoclast induced degradation of the sub-osteoclastic collagenous bone matrix [60-62]. The osteoclast enzyme TRAP is a substrate for cathepsin $\mathrm{K}$ and has been used as a molecular marker for osteoclasts [61,63]. Therefore, the inhibition of osteoclast formation may be a key mechanism for osteoporosis therapeutic agents. Interestingly, our results from TRAP staining and RT-PCR analysis of the gene expression level of cathepsin K, TRAP and RANK observed that NM significantly suppressed osteoclast formation.

Bone remodeling is influenced by many environmental factors and signaling pathways [64]. Previous studies have showed that the MAPK signaling pathway, such as p38, JNK, and ERK, is pivotal for the regulation of osteoblast differentiation, cell proliferation, and bone skeletal development [65]. Yoo et al. demonstrated that $1 \%$ Ca supplementation activates osteoblasts and reduces osteoclasts via the ERK and JNK pathways [34]. Also, Xio et al. reported that the effect of akermanite on BMSCs derived from OVX rats (BMSC-OVX) might be related to the MAPK signaling pathway [49]. In another study, Lin $\mathrm{K}$ et al. reported that substituted calcium silicate-bioactive ceramics upregulated ERK and p38 in BMSC-OVX [66]. We showed that the activation of p38 significantly upregulated in the NM treated group compared to the low-Ca group, both in vitro and in vivo. Thus, our study suggests that NM activates BMP-2/ RUNX2/p-SMAD 1/5/8 induced osteoblast differentiation and inhibits TRAP/RANK-induced osteoclastogenesis via the p38 pathway in the OVX rat model.

\section{Conclusions}

For the first time, our study observed that natural Ca-type NM enhanced osteoblast proliferation, osteogenic differentiation, mineralization, and expression of osteoblast differentiation genes. NM improved proliferation, ALP activity, mineralization, and expression of osteoblast differentiation markers (BMP-2, p-SMAD 1/5/8, RUNX2, Wnt3a, osteocalcin, and COL-1) in an osteoblastic cell line in vitro and in a model of osteoporosis in vivo. In addition, our results from TRAP staining of the osteoclast differentiation markers TRAP, cathepsin $\mathrm{K}$, and RANK showed that NM could significantly suppress osteoclast formation (Figure 8). The findings of our study suggest that the anti-osteoporosis effects of NM on the induction of osteoblasts and reduction in osteoclast formation and may help to explain the important role of clay for the treatment of bone metabolism disorders.

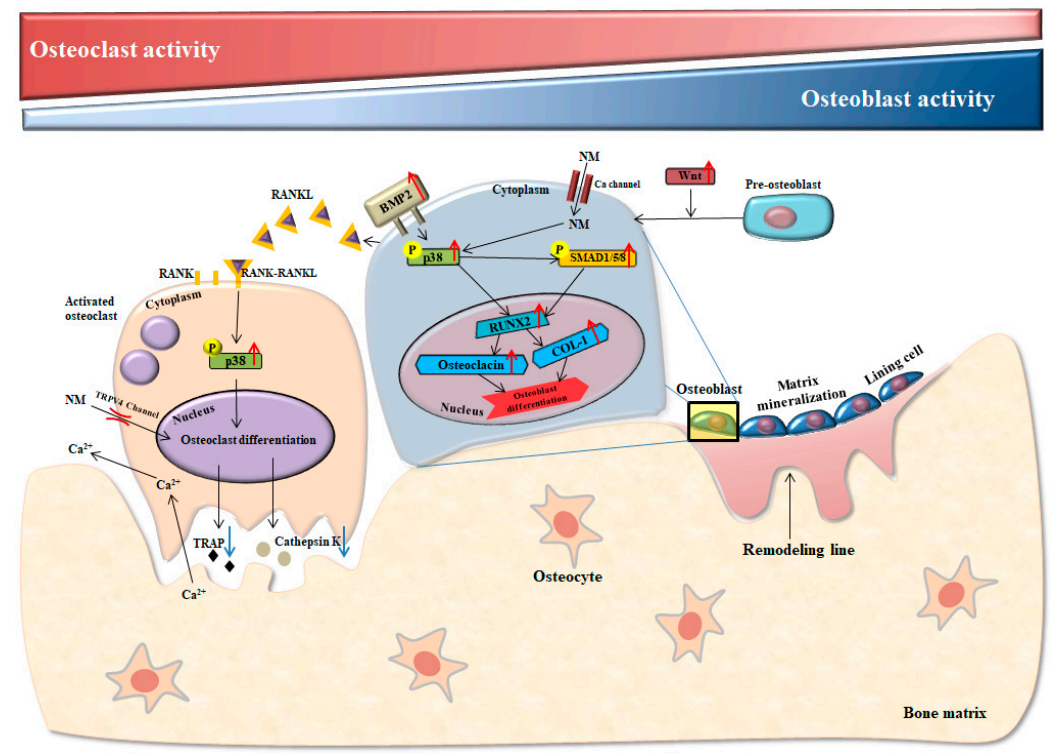

Figure 8. Effect of nano-montmorillonite on osteoblastogenesis and osteoclastogenesis. 
Supplementary Materials: The following are available online at http://www.mdpi.com/2079-4991/10/2/230/s1: Table S1: Bodyweight and food intake. Table S2: Primers used for RT-PCR analysis. Table S3: Composition of the experimental diets. Figure S1: In vivo biochemical analyses.

Author Contributions: Conceptualization, J.H.A.; investigation, G.-J.K., D.K., and D.K.; validation, K.-J.L., J.W.C., and J.H.A.; visualization, G.-J.K., D.K., and D.K.; original draft of manuscript, D.K., G.-J.K., and J.H.A.; writing-review and editing, G.-J.K., K.-H.C. and J.H.A. All authors have read and agreed to the published version of the manuscript.

Funding: This research was supported by the Basic Research Project of the Korea Institute of Geoscience and Mineral Resources (KIGAM) funded by the Ministry of Science and ICT of Korea, and by the Basic Science Research Program through the National Research Foundation of Korea (NRF-2016R1D1A1B04935060 and NRF-2018R1D1A1B07048282).

Conflicts of Interest: The authors declare no conflict of interest. The sponsors had no role in the design, execution, interpretation, or writing of the study.

\section{References}

1. Sawhney, B.L.; Jackson, M.L. Soil montmorillonite formulas. Proc. Soil Sci. Soc. Am. 1958, 22, 115-118. [CrossRef]

2. Röhl, W.; von Rybinski, W.; Schwuger, M.J. Adsorption of surfactants on low-charged layer silicates. Part I: Adsorption of cationic surfactants. Prog. Colloid Polym. Sci. 1991, 84, $206-214$.

3. Kaufhold, S.; Dohrmann, R.; Ufer, K.; Meyer, F.M. Comparison of methods for the bentonites. Appl. Clay Sci. 2002, 22, 145-151. [CrossRef]

4. Abdou, M.I.; Al-Sabagh, A.M.; Dardir, M.M. Evaluation of Egyptian bentonite and nano-bentonite as drilling mud. Egyptian J. Petrol. 2013, 22, 53-59. [CrossRef]

5. Mahto, V.; Sharma, V.P. Rheological study of a water based oil well drilling fluid. J. Pet. Sci. Eng. 2004, 45, 123-128. [CrossRef]

6. Miles, R.D.; Henry, P.R. Safety of improved Milbond-TX ${ }^{\circledR}$ when fed in broiler diets at greater than recommended levels. Anim. Feed Sci. Technol. 2007, 138, 309-317. [CrossRef]

7. Peng, X.; Luan, Z.; Zhang, H. Montmorillonite-Cu(II)/Fe(III) oxides magnetic material as adsorbent for removal of humic acid and its thermal regeneration. Chemosphere 2006, 63, 300-306. [CrossRef]

8. Moraes, J.D.D.; Bertolino, S.R.A.; Cuffini, S.L.; Ducart, D.F.; Bretzke, P.E.; Leonardi, G.R. Clay minerals: Properties and applications to dermocosmetic products and perspectives of natural raw materials for therapeutic purposes-A review. Int. J. Pharm. 2017, 534, 213-219. [CrossRef]

9. Elmore, A.R. Cosmetic ingredient review expert panel. Final report on the safety assessment of aluminum silicate, calcium silicate, magnesium aluminum silicate, magnesium silicate, magnesium trisilicate, sodium magnesium silicate, zirconium silicate, attapulgite, bentonite, Fuller's earth, hectorite, kaolin, lithium magnesium silicate, lithium magnesium sodium silicate, montmorillonite, pyrophyllite, and zeolite. Int. J. Toxicol. 2003, 22, 37-102.

10. Fowler, J.F., Jr. A skin moisturizing cream containing Quaternium-18-Bentonite effectively improves chronic hand dermatitis. J. Cutan. Med. Surg. 2001, 5, 201-205. [CrossRef]

11. Dardir, F.M.; Mohamed, A.S.; Abukhadra, M.R.; Ahmed, E.A.; Soliman, M.F. Cosmetic and pharmaceutical qualifications of Egyptian bentonite and its suitability as drug carrier for Praziquantel drug. Eur. J. Pharm. Sci. 2018, 115, 320-329. [CrossRef] [PubMed]

12. Galambos, M.; Suchanek, P.; Rosskopfova, O. Sorption of anthropogenic radionuclides on natural and synthetic inorganic sorbents. J. Radioanal. Nucl. Chem. 2012, 293, 613-633. [CrossRef]

13. Kahr, G.; Madsen, F.T. Determination of the cation exchange capacity and the surface area of bentonite, illite and kaolinite by methylene blue adsorption. Appl. Clay Sci. 1995, 9, 327-336. [CrossRef]

14. Lee, J.O.; Lim, J.G.; Kang, I.M.; Kwon, S. Swelling pressures of compacted Ca-bentonite. Eng. Geol. 2012, 129-130, 20-26. [CrossRef]

15. Babel, S.; Kurniawan, T.A. Low-cost adsorbents for heavy metals uptake from contaminated water: a review. J. Hazard. Mater. 2003, 97, 219-243. [CrossRef]

16. Vicente-Hernandez, M.A.; Sanchez-Camazano, M.; Sanchez-Martin, M.J. Adsorption and desorption of n-methyl-8-hydroxy quinoline methyl sulfate on smectite and the potential use of the clay-organic product as an ultraviolet radiation collector. Clay Min. 1989, 37, 157-163. [CrossRef] 
17. Song, J.; Li, Y.L.; Hu, C.H. Effects of copper-exchanged montmorillonite, as alternative to antibiotic, on diarrhea, intestinal permeability and proinflammatory cytokine of weanling pigs. Appl. Clay Sci. 2013, 77-78, 52-55. [CrossRef]

18. Phillips, T.D.; Afriyie-Gyawu, E.; Williams, J.; Huebner, H.; Ankrah, N.A.; Ofori-Adjei, D.; Jolly, P.; Johnson, N.; Taylor, J.; Marroquin-Cardona, A.; et al. Reducing human exposure to aflatoxin through the use of clay: A review. Food Addit. Conta. 2007, 25, 134-145. [CrossRef]

19. Linares, C.F.; Torres, A. Modified bentonite with $\mathrm{Na}_{2} \mathrm{CO}_{3}$ as possible antacid medicament. Stud. Surf. Sci. Catal. 2005, 158, 2073-2080.

20. Lee, E.S.; Song, E.J.; Lee, S.Y.; Park, S.L.; Kim, D.; Kim, D.; Kim, D.; Kim, J.H.; Lim, S.I.; Nam, Y.D. Effects of bentonite Bgp35b-p on the gut microbiota of mice fed a high-fat diet. J. Sci. Food Agric. 2018, 98, 4369-4373. [CrossRef]

21. Xu, P.; Dai, S.; Wang, J.; Zhang, J.; Liu, J.; Wang, F.; Zhai, Y. Preventive obesity agent montmorillonite adsorbs dietary lipids and enhances lipid excretion from the digestive tract. Sci. Rep. 2016, 6, 19459. [CrossRef] [PubMed]

22. Mieszawska, A.J.; Llamas, J.G.; Vaiana, C.A.; Kadakia, M.P.; Naik, R.R.; Kaplan, D.L. Clay enriched silk biomaterials for bone formation. Acta Biomater. 2011, 7, 3036-3041. [CrossRef] [PubMed]

23. Katti, K.S.; Katti, D.R.; Dash, R. Synthesis and characterization of a novel chitosan/montmorillonite/hydroxyapatite nanocomposite for bone tissue engineering. Biomed. Mater. 2008, 3, 034122. [CrossRef] [PubMed]

24. Haroun, A.A.; Gamal-Eldeen, A.; Harding, D.R. Preparation, characterization and in vitro biological study of biomimetic three-dimensional gelatin-montmorillonite/cellulose scaffold for tissue engineering. J. Mater. Sci. Mater. Med. 2009, 20, 2527-2540. [CrossRef]

25. Khajuria, D.K.; Razdan, R.; Mahapatra, D.R. Additive effects of zoledronic acid and propranolol on bone density and biochemical markers of bone turnover in osteopenic ovariectomized rats. Rev. Bras. Reumatol. 2015, 55, 103-112. [CrossRef]

26. Weitzmann, M.N.; Pacifici, R. Estrogen deficiency and bone loss: An inflammatory tale. J. Clin. Investig. 2006, 116, 1186-1194. [CrossRef]

27. Zhang, Y.; Mukwaya, E.; Pan, H.; Li, X.M.; Yang, J.L.; Ge, J.; Wang, H.Y. Combination therapy of Chinese herbal medicine Fructus Ligustri Lucidi with high calcium diet on calcium imbalance induced by ovariectomy in mice. Pharm. Biol. 2015, 53, 1082-1085. [CrossRef]

28. Han, N.R.; Kim, H.Y.; Yang, W.M.; Jeong, H.J.; Kim, H.M. Glutamic acid ameliorates estrogen deficiency-induced menopausal-like symptoms in ovariectomized mice. Nutr. Res. 2015, 35, 774-783. [CrossRef]

29. Pravina, P.; Sayaji, D.; Avinash, M. Calcium and its role in human body. Int. J. Res. Pharm. Biomed. Sci. 2013, 4, 659-668.

30. Divittorio, G.; Jackson, K.L.; Chindalore, V.L.; Welker, W.; Walker, J.B. Examining the relationship between bone mineral density and fracture risk reduction during pharmacologic treatment of osteoporosis. Pharmacotherapy 2006, 26, 104-114. [CrossRef]

31. Durão, S.F.; Gomes, P.S.; Colaço, B.J.; Silva, J.C.; Fonseca, H.M.; Duarte, J.R.; Felino, A.C.; Fernandes, M.H. The biomaterial-mediated healing of critical size bone defects in the ovariectomized rat. Osteoporos. Int. 2014, 25, 1535-1545. [CrossRef] [PubMed]

32. Heaney, R.P.; Dowell, M.S.; Barger-Lux, M.J. Absorption of calcium as the carbonate and citrate salts, with some observations on method. Osteoporos. Int. 1999, 9, 19-23. [CrossRef] [PubMed]

33. Gong, H.; Li, W.; Lu, C.; Liu, J. Preventive and therapeutic effects of calcium lactate on osteoporosis in aged ovariectomized rats. Wei Sheng Yan Jiu 1998, 27, 402-404. [PubMed]

34. Yoo, H.S.; Kim, G.J.; Song, D.H.; Chung, K.H.; Lee, K.J.; Kim, D.H.; An, J.H. Calcium supplement derived from Gallus gallus domesticus promotes BMP-2/RUNX2/SMAD5 and suppresses TRAP/RANK expression through MAPK signaling activation. Nutrients 2017, 9, 504. [CrossRef] [PubMed]

35. Anke, M.; Kramer, K.; Glei, M.; Muller, M. Effects of oral bentonite (Fenamin R) on major and trace element incorporation in various tissues and milk of ruminants. 2. Major elements. Mengen und Spurenelemente 1992, 12Arbeitstagung-Leipzig-12/13-Dezember, 435-442.

36. Dembinski, Z.; Wieckowski, W.; Kulinska, A. Use of bentonite produced in Poland for gastroinal disease of newborn calves. Medycyna Weterynaryjna 1985, 41, 359-362. 
37. Ferrage, E.; Lanson, B.; Sakharov, B.A.; Drits, V.A. Investigation of smectite hydration properties by modeling experimental X-ray diffraction patterns: Part I. Montmorillonite hydration properties. Am. Miner. 2005, 90, 1358-1374. [CrossRef]

38. Keren, R.; Shainberg, I. Water vapor isotherms and heat of immersion of Na/Ca-montmorillonite systems-I: homoionic clay. Clay Min. 1975, 23, 193-200. [CrossRef]

39. Viani, A.; Gualtieri, A.F.; Artioli, G. The nature of disorder in montmorillonite by simulation of X-ray powder patterns. Am. Miner. 2002, 87, 966-975. [CrossRef]

40. Poli, A.L.; Batista, T.; Schmitt, C.C.; Gessner, F.; Neumann, M.G. Effect of sonication on the particle size of montmorillonite clays. J. Colloid. Interf. Sci. 2008, 325, 386-390. [CrossRef]

41. Llanos, J.H.R.; Tadini, C.C. Preparation and characterization of bio-nanocomposite films based on cassava starch or chitosan, reinforced with montmorillonite or bamboo nanofibers. Int. J. Biol. Macromol. 2018, 107, 371-382. [CrossRef] [PubMed]

42. Greenblatt, M.B.; Shim, J.H.; Glimcher, L.H. Mitogen-activated protein kinase pathways in osteoblasts. Annu. Rev. Cell Dev. Biol. 2013, 29, 63-79. [CrossRef] [PubMed]

43. Stein, G.S.; Lian, J.B.; Owen, T.A. Relationship of cell growth to the regulation of tissue-specific gene expression during osteoblast differentiation. FASEB J. 1990, 4, 3111-3123. [CrossRef] [PubMed]

44. Franceschi, R.T.; Ge, C. Control of the osteoblast lineage by mitogen-activated protein kinase signaling. Curr. Mol. Biol. Rep. 2017, 3, 122-132. [CrossRef]

45. Gibbs, D.M.R.; Black, C.R.M.; Hulsart-Billstrom, G.; Shi, P.; Scarpa, E.; Oreffo, R.O.C.; Dawson, J.I. Bone induction at physiological doses of BMP through localization by clay nanoparticle gels. Biomaterials 2016, 99, 16-23. [CrossRef]

46. Nordin, B.E.C.; Need, A.G.; Morris, H.A.; Horowitz, M.; Robertson, W.G. Evidence for a renal calcium leak in postmenopausal women. J. Clin. Endocrinol. Metab. 1991, 72, 401-407. [CrossRef]

47. O’Brien, F.J.; Brennan, O.; Kennedy, O.D.; Lee, T.C. Microcracks in cortical bone: how do they affect bone biology? Curr. Osteoporos. Rep. 2005, 3, 39-45. [CrossRef]

48. Hsu, P.Y.; Tsai, M.T.; Wang, S.P.; Chen, Y.J.; Wu, J.; Hsu, J.T. Cortical bone morphological and trabecular bone microarchitectural changes in the mandible and femoral neck of ovariectomized rats. PLoS ONE 2016, 11, e0154367. [CrossRef]

49. Xia, L.; Yin, Z.; Mao, L.; Wang, X.; Liu, J.; Jiang, X.; Zhang, Z.; Lin, K.; Chang, J.; Fang, B. Akermanite bioceramics promote osteogenesis, angiogenesis and suppress osteoclastogenesis for osteoporotic bone regeneration. Sci. Rep. 2016, 6, 22005. [CrossRef]

50. Kim, B.S.; Kang, H.J.; Park, J.Y.; Lee, J. Fucoidan promotes osteoblast differentiation via JNK- and ERK-dependent BMP2-Smad 1/5/8 signaling in human mesenchymal stem cells. Exp. Mol. Med. 2015, 47, e128. [CrossRef]

51. Jeon, E.J.; Lee, D.H.; Kim, Y.J.; Ahn, J.; Kim, M.J.; Hwang, J.T.; Hur, J.; Kim, M.; Jang, Y.J.; Ha, T.Y.; et al. Effects of yuja peel extract and its flavanones on osteopenia in ovariectomized rats and osteoblast differentiation. Mol. Nutr. Food Res. 2016, 60, 2587-2601. [CrossRef]

52. Das, S.S.; Hussain, K.; Singh, S.; Hussain, A.; Faruk, A.; Tebyetekerwa, M. Laponite-based nanomaterials for biomedical applications: A review. Curr. Pharm. Des. 2019, 25, 424-443. [CrossRef] [PubMed]

53. Zhang, S.; Sun, J.; Xu, Y.; Qian, S.; Wang, B.; Liu, F.; Liu, X. Biological behavior of osteoblast-like cells on titania and zirconia films deposited by cathodic arc deposition. Biointerphases. 2012, 7, 60. [CrossRef] [PubMed]

54. Kushwaha, P.; Khedgikar, V.; Gautam, J.; Dixit, P.; Chillara, R.; Verma, A.; Thakur, R.; Mishra, D.P.; Singh, D.; Maurya, R.; et al. A novel therapeutic approach with Caviunin-based isoflavonoid that en routes bone marrow cells to bone formation via BMP2/Wnt- $\beta$-catenin signaling. Cell Death Dis. 2014, 5, e1422. [CrossRef] [PubMed]

55. Dai, J.; Li, Y.; Zhou, H.; Chen, J.; Chen, M.; Xiao, Z. Genistein promotion of osteogenic differentiation through BMP2/SMAD5/RUNX2 signaling. Int. J. Biol. Sci. 2013, 9, 1089-1098. [CrossRef] [PubMed]

56. Komori, T.; Yagi, H.; Nomura, S.; Yamaguchi, A.; Sasaki, K.; Deguchi, K.; Shimizu, Y.; Bronson, R.T.; Gao, Y.H.; Inada, M.; et al. Targeted disruption of Cbfa1 results in a complete lack of bone formation owing to maturational arrest of osteoblasts. Cell 1997, 89, 755-764. [CrossRef]

57. Gaur, T.; Lengner, C.J.; Hovhannisyan, H.; Bhat, R.A.; Bodine, P.V.; Komm, B.S.; Javed, A.; van Wijnen, A.J.; Stein, J.L.; Stein, G.S.; et al. Canonical WNT signaling promotes osteogenesis by directly stimulating Runx2 gene expression. J. Biol. Chem. 2005, 280, 33132-33140. [CrossRef] 
58. Gori, F.; Hofbauer, L.C.; Dunstan, C.R.; Spelsberg, T.C.; Khosla, S.; Riggs, B.L. The expression of osteoprotegerin and RANK ligand and the support of osteoclast formation by stromal-osteoblast lineage cells is developmentally regulated. Endocrinology 2000, 141, 4768-4776. [CrossRef]

59. Raggatt, L.J.; Partridge, N.C. Cellular and molecular mechanisms of bone remodeling. J. Biol. Chem. 2010, 285, 25103-25108. [CrossRef]

60. Zenger, S.; Hollberg, K.; Ljusberg, J.; Norgård, M.; Ek-Rylander, B.; Kiviranta, R.; Andersson, G. Proteolytic processing and polarized secretion of tartrate-resistant acid phosphatase is altered in a subpopulation of metaphyseal osteoclasts in cathepsin K-deficient mice. Bone 2007, 41, 820-832. [CrossRef]

61. Bossard, M.J.; Tomaszek, T.A.; Thompson, S.K.; Amegadzie, B.Y.; Hanning, C.R.; Jones, C. Proteolytic activity of human osteoclast cathepsin K. Expression, purification, activation, and substrate identification. J. Biol. Chem. 1996, 271, 12517-12524. [CrossRef] [PubMed]

62. Xia, L.; Kilb, J.; Wex, H.; Li, Z.; Lipyansky, A.; Breuil, V.; Stein, L.; Palmer, J.T.; Dempster, D.W.; Brömme, D. Localization of rat cathepsin $\mathrm{K}$ in osteoclasts and resorption pits: inhibition of bone resorption and cathepsin K-activity by peptidyl vinyl sulfones. Biol. Chem. 1999, 380, 679-687. [CrossRef] [PubMed]

63. Bernhardt, A.; Koperski, K.; Schumacher, M.; Gelinsky, M. Relevance of osteoclast-specific enzyme activities in cell-based in vitro resorption assays. Eur. Cells Mater. 2017, 18, 28-42. [CrossRef] [PubMed]

64. Rubin, J.; Rubin, C.; Jacobs, C.R. Molecular pathways mediating mechanical signaling in bone. Gene 2006, 367, 1-16. [CrossRef]

65. Eddie, R.C.; Beatriz, G.; Francesc, V. p38 MAPK signaling in osteoblast differentiation. Front. Cell Dev. Biol. 2016, 4, 1-20.

66. Lin, K.; Xia, L.; Li, H.; Jiang, X.; Pan, H.; Xu, Y.; Lu, W.W.; Zhang, Z.; Chang, J. Enhanced osteoporotic bone regeneration by strontium-substituted calcium silicate bioactive ceramics. Biomaterials 2013, 34, 10028-10042. [CrossRef]

(C) 2020 by the authors. Licensee MDPI, Basel, Switzerland. This article is an open access article distributed under the terms and conditions of the Creative Commons Attribution (CC BY) license (http://creativecommons.org/licenses/by/4.0/). 